\title{
Speciation of heavy metals in marine sediments from the East China Sea by ICP-MS with sequential extraction
}

\author{
Chun-gang Yuan, Jian-bo Shi, Bin He, Jing-fu Liu, Li-na Liang, Gui-bin Jiang* \\ Key Laboratory of Environmental Chemistry and Ecotoxicology, Research Center for Eco-Environmental Sciences, Chinese Academy of Sciences, \\ P.O. Box 2871, 100085 Beijing, China
}

Received 12 September 2003; accepted 12 January 2004

\begin{abstract}
Twelve elements (V, Cr, Mn, Fe, Co, Ni, Cu, Zn, Mo, Sn, Cd and Pb) in 24 sediment samples at eight sites (S1-S8) from the East China Sea were analyzed with the BCR sequential extraction (SE) protocol to obtain the metal distribution patterns in this region. The results showed that the heavy metal pollutions in S4 and S8 were more severe than in other sampling sites, especially Cd and $\mathrm{Pb}$ pollution. In the top sediments at $\mathrm{S} 4$ and $\mathrm{S} 8$, both the total contents and the most dangerous non-residual fractions of $\mathrm{Cd}$ and $\mathrm{Pb}$ were extremely high. More than $90 \%$ of the total concentrations of $\mathrm{V}, \mathrm{Cr}$, Mo and $\mathrm{Sn}$ existed in the residual fraction. $\mathrm{Fe}, \mathrm{Co}, \mathrm{Ni}, \mathrm{Cu}$ and $\mathrm{Zn}$ mainly (more than $60 \%$ ) occurred in the residual fraction. While $\mathrm{Mn}, \mathrm{Pb}$ and $\mathrm{Cd}$ dominantly presented in the non-residual fractions in the top sediments. The metal distribution patterns with depth and the correlations between total organic carbon (TOC) and the total Fe-Mn content were also investigated. The results showed that, for most of the elements except Fe, the concentration of elements in fraction A in the top sediments was higher than that in other depth. The similar rule was also found in fraction $\mathrm{B}$ but not in fraction $\mathrm{C}$. Besides, the distributions of $\mathrm{V}, \mathrm{Cd}$ in fraction $\mathrm{B}$ and $\mathrm{Pb}, \mathrm{Cd}, \mathrm{Cu}$ in fraction $\mathrm{C}$ might be affected by TOC.
\end{abstract}

(C) 2004 Elsevier Ltd. All rights reserved.

Keywords: Speciation; Heavy metals; Sequential extraction; Marine sediments

\section{Introduction}

Many negative effects have been done on human health by the environmental pollution of heavy metals. The remediation of heavy metal pollution is often problematic due to their persistence and not degradability in the environment. As a sink and source, sediments constitute a reservoir of bioavailable trace elements and play an important role in geochemical cycles. Much concern has been focused on the investigation of the total metal contents in sediments. However, it cannot provide sufficient information about mobility, bioavailability and toxicity of metals. Their properties depend not only on their total concentration but also on the physicochemical form they occur (Davidson et al., 1994), which has been described as "speciation" (Ure et al., 1993).

Metals are distributed throughout sediment components and associated with them in various ways including ion exchange, adsorption, precipitation, and complexation. They

\footnotetext{
* Corresponding author. Fax: +86-10-62849179.

E-mail address: gbjiang@mail.rcees.ac.cn (G. Jiang).
}

are not permanently fixed by sediment. Changes in environment conditions, such as acidification, redox potential or organic ligand concentrations, can cause mobilization of element from solid to liquid phase and cause contamination of surrounding waters.

Sequential extraction (SE) (Tessier et al., 1979) can provide information about the identification of the main binding sites, the strength of metal binding to the particulates and the phase associations of trace elements in sediment. This could help us to understand the geochemical processes governing heavy metal mobilization and potential risks induced.

Among the sequential extraction schemes proposed to investigate the distribution of heavy metals in soil and sediment, the five-step and six-step extraction schemes developed by Tessier et al. (1979) and Kersten and Forstner (1986), respectively, were used most widely. Following these two basic schemes, some modified procedures with different sequences of reagents or operational conditions have been developed (Borovec et al., 1993; Campanella et al., 1995; Zdenek, 1996; Gomez Ariza et al., 2000). Considering the diversity of procedures and lack of uniformity in different 
protocols, a BCR (now the European Community (EC) Standards Measurement and Testing Programme) method was proposed (Ure et al., 1993). It harmonized different extraction schemes for sediment analysis. This procedure was applied and accepted by a large group of specialists (Salomons, 1993; Fiedler et al., 1994; Ho and Evans, 1997; Lopez-Sanchez et al., 1998; Usero et al., 1998; Martin et al., 1998; Agnieszka and Wieslaw, 2002) despite some shortcomings in the sequential extraction procedures (Ramos et al., 1994; Tu et al., 1994).

In this study, 24 sediment samples from the East China Sea were analyzed by the BCR sequential extraction method to obtain the information of vertical and planar distributions of heavy metals in this region. The correlations between the distribution of heavy metals and the content of total organic carbon (TOC) were measured and discussed to evaluate the effects of TOC on the distribution of the studied elements.

\section{Materials and methods}

\subsection{Sampling locations description}

Twenty-four sediment samples from eight sampling locations in the East China Sea (one part of the Pacific
Ocean) were selected. In this region, two rivers, Yangtze River, the longest river in China, and Qiantang River flow into Yangtze estuary and Hangzhou Bay and reach the sea at last. Many docks are spread along Yangtze estuary and Hangzhou Bay, which might cause pollution by ship voyages and waste discharges. Furthermore, some developed cities, such as Shanghai, are located in this area. With the rapid development of these cities in recent years, a lot of industrial and domestic solid waste and wastewater was discharged into Yangtze River and Qiantang River or into the sea directly. Red tides occurred several times in 1990s in this area due to the severe pollution. Quantities of fish and shellfish have died, resulting in very large economic losses during the period.

The eight sampling locations and the map of the East China Sea are shown in Fig. 1, and the geographic positions are listed in Table 1. The sampling sites S4 and S5 are located at the junction of the two rivers (Yangtze River and Qiantang River) and close to Changjiang Estuary and Hangzhou Bay. S3 lies at a similar latitude to S4, but is at north of Changjiang River flow direction, hence, it is not as greatly influenced by Changjiang River as S4 and S5 (Chen et al., 2001). S8 is close to Ningbo city, a large seaport. S7 is close to the fishing farm of Zhoushan Archipelago. Other sampling sites (S1, S2 and S6) are more distant from the land.

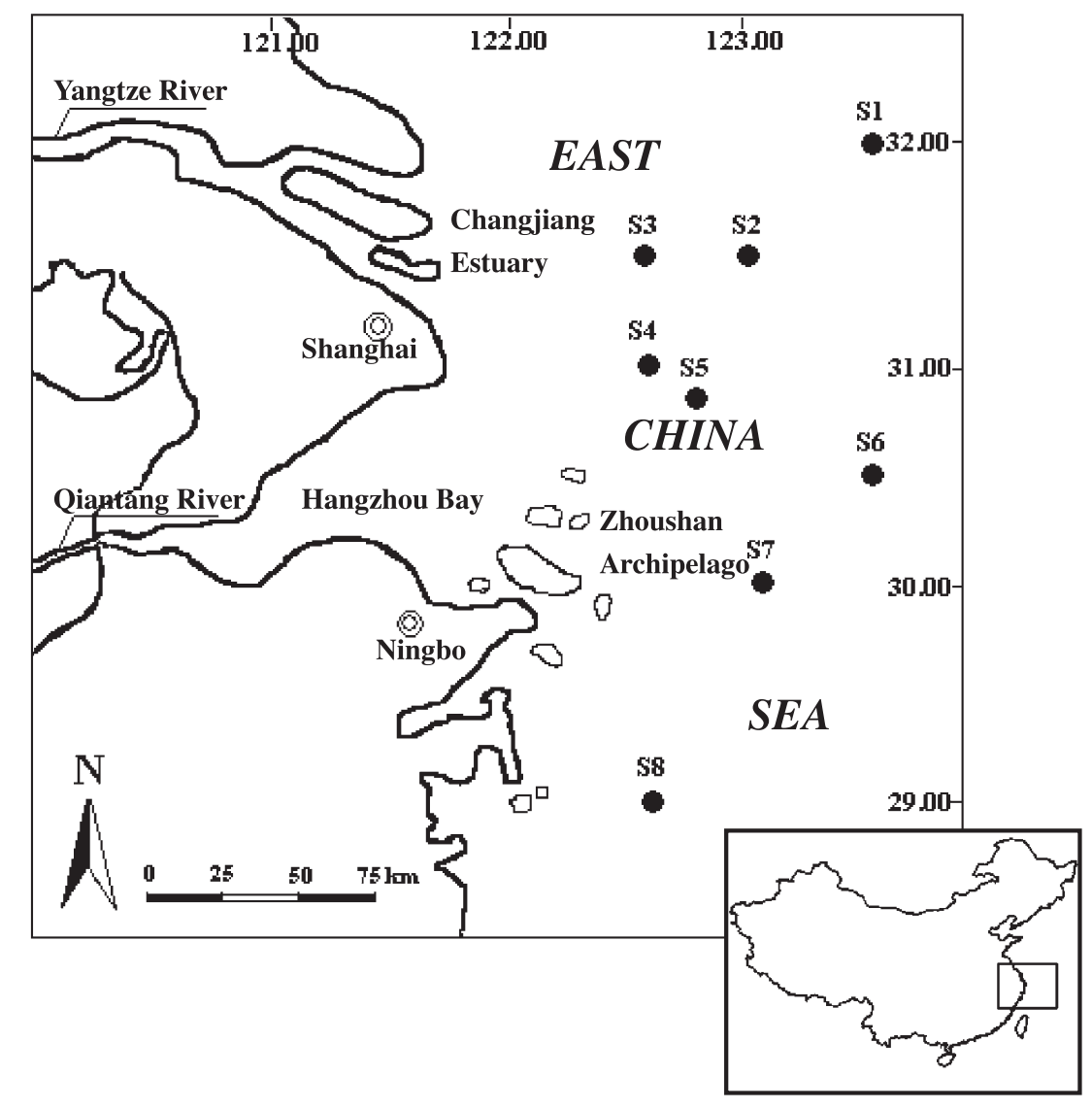

Fig. 1. Map of the East China Sea with locations of sampling sites. 
Table 1

The sampling geographic position, $\mathrm{pH}$ value and TOC

\begin{tabular}{|c|c|c|c|}
\hline Sampling site & $\begin{array}{l}\text { Geographic } \\
\text { position }\end{array}$ & $\mathrm{pH}$ value & $\begin{array}{l}\text { TOC } \\
{\left[\mathrm{mg} \mathrm{g}^{-1}\right]}\end{array}$ \\
\hline $\mathrm{S} 1$ & $\begin{array}{l}31^{\circ} 59.893^{\prime} \mathrm{N} \\
123^{\circ} 30.195^{\prime} \quad \mathrm{E}\end{array}$ & 6.45 & 3.03 \\
\hline $\mathrm{S} 2$ & $\begin{array}{l}31^{\circ} 30.092^{\prime} \quad \mathrm{N} \\
123^{\circ} 00.272^{\prime} \quad \mathrm{E}\end{array}$ & 6.61 & 1.42 \\
\hline $\mathrm{S} 3$ & $\begin{array}{l}31^{\circ} 30.061^{\prime} \mathrm{N} ; \\
122^{\circ} 30.679^{\prime} \mathrm{E}\end{array}$ & 6.41 & 3.76 \\
\hline $\mathrm{S} 4$ & $\begin{array}{l}31^{\circ} 00.460^{\prime} \mathrm{N} ; \\
122^{\circ} 29.870^{\prime} \quad \mathrm{E}\end{array}$ & 6.08 & 6.98 \\
\hline S5 & $\begin{array}{l}30^{\circ} 41.866^{\prime} \mathrm{N} \\
122^{\circ} 43.798^{\prime} \mathrm{E}\end{array}$ & 6.42 & 9.26 \\
\hline S6 & $\begin{array}{l}30^{\circ} 30.603^{\prime} \mathrm{N} \\
123^{\circ} 29.623^{\prime} \quad \mathrm{E}\end{array}$ & 6.45 & 2.39 \\
\hline S7 & $\begin{array}{l}30^{\circ} 00.220^{\prime} \mathrm{N} \\
123^{\circ} 00.507^{\prime} \mathrm{E}\end{array}$ & 6.41 & 6.55 \\
\hline S8 & $\begin{array}{l}29^{\circ} 00.098^{\prime} \mathrm{N} \\
122^{\circ} 30.665^{\prime} \quad \mathrm{E}\end{array}$ & 6.24 & 9.24 \\
\hline
\end{tabular}

\subsection{Sampling and sample pretreatment}

Twenty-four sediment samples were collected at the eight locations in November 2002. A research vessel, Science No. 1 , was utilized during that voyage. The whole voyage took 11 days.

The sediments were collected from the bottom of the sea using a self-gravity sampling implement consisting of a 60$\mathrm{cm}$ plastic sampling tube. Upon retrieving the core in deck, the top sediment $(0-1 \mathrm{~cm})$ was taken and the sediments were subsampled with a plastic spatula. The wet sediment samples were sieved $(<63 \mu \mathrm{m})$, then sealed in PTFE bags and refrigerated $\left(-4{ }^{\circ} \mathrm{C}\right)$ immediately to avoid changes in heavy metal distribution among different phases. Because of their high risk of being polluted (Che et al., 2002), two sediment cores were collected at S4 and S8 as typical sites to investigate the distribution variation of element speciation with depth.

The dry samples are easier to be treated compared to the wet samples, but it was reported that sample drying could alter the solid phase distribution of metals (Davidson et al., 1999). Therefore, it is more reasonable to use the wet samples during the experiment. In our work, to avoid the error occurring and achieve more realistic results, wet samples were used for the sequential extraction procedure. At the same time, the wet/dry ratios were determined by heating at $105{ }^{\circ} \mathrm{C}$ in aluminous plates until constant weight. The data reported in this paper are calculated as dry weight.

\subsection{Apparatus}

Inductively coupled plasma-mass spectrometry (ICP-MS, Agilent 7500, Agilent, USA) was applied for determination of the heavy metals in this work. A total organic carbon analyzer (Apollo 9000, Tekmar-Dohrmann, USA) was used to determine the contents of the total organic carbon (TOC) in the sediment samples.

An ultracentrifuge was used for the centrifugation of the extracts. A horizontal rotator shaker was used for the extraction and a $\mathrm{pH}$ value meter was used to detect the $\mathrm{pH}$ values of the sediment samples. All the glass containers used were soaked in $50 \% \mathrm{HNO}_{3}(\mathrm{~V} / \mathrm{V})$ and rinsed with deionized water. The extracts from the samples were stored in PTFE tubes and stored at $4{ }^{\circ} \mathrm{C}$ before analysis.

\subsection{Reagents}

Deionized (DI) water supplied by EASYpure LF System (18 M $\Omega$ ) (Model D7382-33, Barnstead Thermolyne, USA) was used throughout. Superpure nitric acid, hydrogen peroxide, hydrofluoric acid and analytical grade acetic acid, hydroxylamine hydrochloride and ammonium acetate (Beijing Chemical Factory, China) were used for extraction and wet digestion. Calibration solutions were prepared in deionized water from stock solution (Agilent).

\section{5. $p H$ measurement and TOC analysis}

The $\mathrm{pH}$ values of the samples were determined in the deionized water with a ratio of 1:5 (sediment to water) by using a $\mathrm{pH}$ meter. The TOC content was determined by a TOC analyzer. The $\mathrm{pH}$ values and TOC contents are listed in Table 1.

\subsection{Sequential extraction method}

The BCR three-step sequential extraction procedure was used to obtain the information about the nonresidual speciation distributions of metals. The extraction

Table 2

Reagent used at each extraction step and the extraction fraction of sediments in the sequential extraction procedure

\begin{tabular}{|c|c|c|c|}
\hline $\begin{array}{l}\text { Extraction } \\
\text { step }\end{array}$ & $\begin{array}{l}\text { Extraction } \\
\text { reagent and } \\
\text { method }\end{array}$ & Fraction & $\begin{array}{l}\text { Extracted } \\
\text { components }\end{array}$ \\
\hline A & $\begin{array}{l}\text { Acetic acid } \mathrm{CH}_{3} \mathrm{COOH} \\
\left(0.11 \mathrm{~mol}^{-1}\right) \\
\text { pH } 2.85,16 \mathrm{~h}\end{array}$ & $\begin{array}{l}\text { Fraction A, } \\
\text { Acid soluble }\end{array}$ & $\begin{array}{l}\text { Exchangeable } \\
\text { ions and } \\
\text { carbonates }\end{array}$ \\
\hline B & $\begin{array}{l}\text { Hydroxyl ammonium } \\
\text { chloride } \mathrm{NH}_{2} \mathrm{OH} \cdot \mathrm{HCl} \\
\left(0.1 \mathrm{~mol}^{-1}\right), \mathrm{pH} 2\end{array}$ & $\begin{array}{l}\text { Fraction B, } \\
\text { Reducible }\end{array}$ & $\begin{array}{l}\text { Iron- } \\
\text { manganese } \\
\text { oxides }\end{array}$ \\
\hline $\mathrm{C}$ & $\begin{array}{l}\text { Hydrogen peroxide } \\
30 \% \mathrm{H}_{2} \mathrm{O}_{2}\left(8.8 \mathrm{~mol} 1^{-}\right), \\
2 \mathrm{~h} \text { at } 85{ }^{\circ} \mathrm{C} \text {, followed } \\
\text { by } \mathrm{CH}_{3} \mathrm{COONH} 4 \\
\left(1 \mathrm{~mol}^{-1}\right), \mathrm{pH} 2,16 \mathrm{~h}\end{array}$ & $\begin{array}{l}\text { Fraction } \mathrm{C} \text {, } \\
\text { Oxidable }\end{array}$ & $\begin{array}{l}\text { Sulphides/ } \\
\text { organics }\end{array}$ \\
\hline $\mathrm{D}$ & $\begin{array}{l}\text { Mix acid } \mathrm{HNO}_{3} \\
(2 \mathrm{ml})+\mathrm{H}_{2} \mathrm{O}_{2}(2 \mathrm{ml})+ \\
\mathrm{HF}(0.5 \mathrm{ml})\end{array}$ & $\begin{array}{l}\text { Fraction D, } \\
\text { Residual }\end{array}$ & $\begin{array}{l}\text { Metals bound } \\
\text { in lithogenic } \\
\text { minerals }\end{array}$ \\
\hline
\end{tabular}


reagents used and the sediment fractions targeted are illustrated in Table 2. To obtain an indication of the concentration of these elements associated with the residual components of sediment matrix, a fourth step that involves digestion of residue from the third step with mixed acid ( $2 \mathrm{ml} \mathrm{HNO}_{3}$ and $0.5 \mathrm{ml} \mathrm{HF}$ ) was introduced. The digestion of samples was performed in a similar way by using a mixture of $2 \mathrm{ml} \mathrm{HNO}_{3}, 2 \mathrm{ml}$ $\mathrm{H}_{2} \mathrm{O}_{2}$ and $0.5 \mathrm{ml} \mathrm{HF}$ to obtain the total content of elements in sediments.

\section{Results and discussion}

\subsection{Reproducibility and accuracy of the method}

To evaluate the reproducibility and accuracy of the method, a reference sediment material (GBW-07310) was subjected to the BCR protocol. Three subsamples (Sets A, B and $\mathrm{C}$ ) were taken through the $\mathrm{BCR}$ sequential extraction procedure in parallel. The results and the relative standard deviations (R.S.D) are listed in Table 3.

Table 3

Reproducibility of the sequential extraction procedure

\begin{tabular}{|c|c|c|c|c|c|c|c|c|c|}
\hline \multirow[t]{2}{*}{ Element } & \multirow[t]{2}{*}{ Step } & \multicolumn{2}{|c|}{ Set A $(n=5)$} & \multicolumn{2}{|c|}{ Set B $(n=5)$} & \multicolumn{2}{|c|}{ Set C $(n=5)$} & \multirow{2}{*}{$\begin{array}{l}\text { Grand } \\
\text { mean }^{\mathrm{a}}\end{array}$} & \multirow[t]{2}{*}{ R.S.D ${ }^{b}$} \\
\hline & & Mean $^{a}$ & R.S.D ${ }^{b}$ & Mean $^{a}$ & R.S.D ${ }^{b}$ & Mean $^{\mathrm{a}}$ & R.S.D ${ }^{b}$ & & \\
\hline \multirow[t]{4}{*}{$\mathrm{V}$} & A & 0.05 & 5.67 & 0.08 & 4.26 & 0.06 & 6.1 & 0.06 & 25.3 \\
\hline & B & 5.25 & 4.24 & 7.45 & 4.23 & 6.40 & 3.2 & 6.40 & 17.2 \\
\hline & $\mathrm{C}$ & 12.07 & 0.36 & 9.60 & 2.1 & 10.96 & 0.62 & 10.96 & 11.4 \\
\hline & $\mathrm{D}$ & 79.02 & 0.56 & 81.88 & 0.32 & 80.41 & 0.82 & 80.41 & 1.8 \\
\hline \multirow[t]{4}{*}{$\mathrm{Cr}$} & A & 0.49 & 2.75 & 0.68 & 3.10 & 0.60 & 2.62 & 0.60 & 16.4 \\
\hline & B & 2.64 & 1.68 & 2.68 & 0.95 & 2.71 & 0.86 & 2.71 & 3.2 \\
\hline & $\mathrm{C}$ & 19.91 & 0.95 & 18.84 & 0.31 & 19.32 & 0.64 & 19.32 & 2.8 \\
\hline & $\mathrm{D}$ & 93.26 & 0.62 & 88.35 & 0.21 & 90.38 & 0.22 & 90.38 & 2.8 \\
\hline \multirow[t]{4}{*}{$\mathrm{Mn}$} & A & 65.10 & 0.75 & 71.87 & 2.31 & 70.08 & 3.11 & 70.08 & 6.2 \\
\hline & B & 420.98 & 0.86 & 417.30 & 0.62 & 413.03 & 0.49 & 413.03 & 2.6 \\
\hline & $\mathrm{C}$ & 151.69 & 3.44 & 136.68 & 3.22 & 144.90 & 0.13 & 144.90 & 5.2 \\
\hline & $\mathrm{D}$ & 106.26 & 0.89 & 104.04 & 1.96 & 106.65 & 6.21 & 106.65 & 2.6 \\
\hline \multirow[t]{4}{*}{ Co } & A & 0.52 & 1.54 & 0.54 & 0.98 & 0.53 & 2.36 & 0.53 & 2.8 \\
\hline & B & 7.35 & 1.49 & 7.26 & 1.98 & 7.38 & 3.65 & 7.38 & 1.9 \\
\hline & $\mathrm{C}$ & 2.42 & 0.62 & 2.04 & 3.16 & 2.28 & 0.69 & 2.28 & 9.3 \\
\hline & $\mathrm{D}$ & 2.49 & 0.59 & 2.47 & 2.57 & 2.49 & 0.36 & 2.49 & 1.1 \\
\hline \multirow[t]{4}{*}{$\mathrm{Ni}$} & A & 0.78 & 1.44 & 1.00 & 2.01 & 0.85 & 1.59 & 0.88 & 12.9 \\
\hline & B & 3.36 & 2.06 & 3.31 & 1.89 & 3.42 & 1.62 & 3.37 & 1.6 \\
\hline & $\mathrm{C}$ & 8.41 & 1.69 & 8.32 & 0.63 & 8.61 & 0.96 & 8.45 & 1.8 \\
\hline & $\mathrm{D}$ & 14.98 & 2.14 & 14.66 & 0.31 & 14.01 & 3.12 & 14.55 & 3.4 \\
\hline \multirow[t]{4}{*}{$\mathrm{Cu}$} & A & 0.26 & 1.08 & 0.33 & 2.13 & 0.29 & 1.56 & 0.29 & 12.2 \\
\hline & B & 1.66 & 2.18 & 1.78 & 3.02 & 1.59 & 0.95 & 1.68 & 5.7 \\
\hline & $\mathrm{C}$ & 2.52 & 0.76 & 2.72 & 0.65 & 2.81 & 3.33 & 2.68 & 5.6 \\
\hline & $\mathrm{D}$ & 15.18 & 0.66 & 13.55 & 0.96 & 15.04 & 0.21 & 14.59 & 6.2 \\
\hline \multirow[t]{4}{*}{$\mathrm{Zn}$} & A & 4.14 & 1.12 & 4.59 & 1.56 & 4.66 & 3.46 & 4.46 & 6.3 \\
\hline & B & 7.03 & 0.91 & 7.99 & 1.62 & 7.58 & 0.55 & 7.53 & 6.4 \\
\hline & $\mathrm{C}$ & 11.60 & 0.70 & 12.68 & 3.22 & 11.42 & 0.42 & 11.90 & 5.7 \\
\hline & $\mathrm{D}$ & 38.95 & 0.62 & 32.23 & 0.56 & 36.58 & 0.16 & 35.92 & 9.5 \\
\hline \multirow[t]{4}{*}{ Mo } & A & $\mathrm{c}$ & - & $\mathrm{c}$ & - & $\mathrm{c}$ & - & $\mathrm{c}$ & - \\
\hline & B & 0.01 & 3.22 & 0.01 & 4.62 & 0.01 & 7.35 & 0.01 & 5.6 \\
\hline & $\mathrm{C}$ & 0.11 & 0.16 & 0.13 & 0.06 & 0.12 & 0.56 & 0.12 & 5.4 \\
\hline & $\mathrm{D}$ & 1.28 & 0.12 & 1.32 & 0.64 & 1.34 & 0.84 & 1.31 & 2.3 \\
\hline \multirow[t]{4}{*}{$\mathrm{Cd}$} & A & 0.20 & 2.93 & 0.25 & 1.65 & 0.24 & 3.64 & 0.23 & 12.2 \\
\hline & B & 0.46 & 5.07 & 0.43 & 3.56 & 0.48 & 1.48 & 0.46 & 6.1 \\
\hline & $\mathrm{C}$ & 0.13 & 2.19 & 0.12 & 2.79 & 0.11 & 0.99 & 0.12 & 10.2 \\
\hline & $\mathrm{D}$ & 0.18 & 1.23 & 0.17 & 0.68 & 0.19 & 2.16 & 0.18 & 4.5 \\
\hline \multirow[t]{4}{*}{$\mathrm{Sn}$} & A & $\mathrm{c}$ & - & $\mathrm{c}$ & - & c & - & $\mathrm{c}$ & - \\
\hline & B & $\mathrm{c}$ & - & c & - & $\mathrm{c}$ & - & $\mathrm{c}$ & - \\
\hline & $\mathrm{C}$ & $\mathrm{c}$ & - & c & - & c & - & $\mathrm{c}$ & - \\
\hline & $\mathrm{D}$ & 1.82 & 3.12 & 2.02 & 1.65 & 1.95 & 2.46 & 1.93 & 5.2 \\
\hline \multirow[t]{4}{*}{$\mathrm{Pb}$} & A & 0.01 & 5.80 & 0.02 & 3.67 & 0.02 & 1.24 & 0.02 & 34.4 \\
\hline & B & 9.70 & 2.28 & 10.78 & 6.01 & 10.20 & 2.16 & 10.23 & 5.3 \\
\hline & $\mathrm{C}$ & 7.08 & 2.20 & 6.26 & 1.62 & 6.69 & 1.89 & 6.68 & 6.1 \\
\hline & $\mathrm{D}$ & 8.73 & 0.16 & 8.28 & 0.52 & 8.85 & 0.48 & 8.62 & 3.5 \\
\hline
\end{tabular}

\footnotetext{
${ }^{\mathrm{a}}$ Units: $\mu \mathrm{g} \mathrm{g}^{-1}$.

${ }^{\mathrm{b}}$ Units: \%.

${ }^{\mathrm{c}}$ Not detected.
} 
An internal check was performed on the results of the sequential extraction by comparing the total amount of metals extracted by different reagents during the sequential extraction procedure with the results of the total digestion. The recovery of the sequential extraction was calculated as follows:

$$
\begin{aligned}
\text { Recovery }= & {\left[\left(C_{\text {Fraction A }}+C_{\text {Fraction B }}+C_{\text {Fraction C }}\right.\right.} \\
& \left.\left.+C_{\text {Fraction D }}\right) / C_{\text {total digestion }}\right] \times 100
\end{aligned}
$$

Results showed in Table 4 indicate that the sums of the four fractions are in good agreement with the total digestion results with the satisfactory recoveries $(77.7-116.7 \%)$ and the method used is reliable and repeatable.

\subsection{Sequential extraction results}

The concentrations of metals in the marine sediment samples from each extraction step are shown in Figs. 2-4. The discussion on the distribution patterns of elements is divided into four groups depending on the degree of their association with the different phases. V, Cr, Sn and Mo are assigned to a group that are present mainly in the residual fraction (more than $90 \%$ of the total concentration), Co, Ni, $\mathrm{Cu}$ and $\mathrm{Zn}$ in a group presenting in the residual fraction dominantly (ca. $60 \%$ of the total concentration), $\mathrm{Cd}$ and $\mathrm{Pb}$ in a group with the large proportion of the total concentration presenting in the non-residual fractions (FA + FB + FC), while $\mathrm{Fe}$ and $\mathrm{Mn}$ in a group due to their similar properties.

\subsubsection{Vanadium, chromium, tin and molybdenum}

These four elements are mainly in the residual fraction (Fig. 2), representing 95.2-97.8\%, 94.9-98.8\%, 93.7$99.1 \%$ and nearly $100 \%$ of total concentration, respectively. The phase distribution of $\mathrm{Cr}$ in this study is similar to the results reported by Martin et al. (1998), who found that $\mathrm{Cr}$ was mostly retained in the residual fraction. These results indicate that the distribution patterns of these elements in the selected sediments are similar. Metals associated with the residual fraction are likely to be incorporated in aluminosilicate minerals and therefore are unlikely to be released to porewaters through dissociation. The total concentrations of $\mathrm{V}, \mathrm{Cr}$, and Sn were as high as $125.0,87.6$ and $6.4 \mu \mathrm{g} \mathrm{g}^{-1}$ at S8. Since there are only low concentrations of these elements in the non-residual fractions, these elements are unlikely to pose a direct and significant threaten to surroundings. It should be noted that sediments always act as reservoir for metals, their potential risk of pollution to environment must be considered.

\subsubsection{Cobalt, nickel, copper and zinc}

The distribution patterns of these four metals are illustrated in Fig. 3. These metals were found in all of the four operationally defined sediment phases. The dominant phase was in the residual fraction, which accounted for more than $60 \%$ of the total concentration of metals at most of the sampling sites, notably at S8, more than $80 \%$ of the total concentration of metals was in the residual fraction. There was lift variation in phase distribution for $\mathrm{Ni}, \mathrm{Cu}$ and $\mathrm{Zn}$ among sampling sites except for S5, in which $22 \%$ of the total $\mathrm{Zn}$ was in the fraction $\mathrm{B}$ (the reducible or ironmanganese oxide fraction). Similar result for $\mathrm{Zn}$ was obtained at its adjacent site (S4). The variation of Co was more significant than $\mathrm{Ni}, \mathrm{Cu}$ and $\mathrm{Zn}$. For example, $38 \%$ of total concentration of $\mathrm{Co}$ was found in the non-residual fractions at site S4, but only $9 \%$ of total Co was found in these fractions at S5.

The dominant proportion of $\mathrm{Ni}$ was in the residual fraction, which was in agreement with the literatures (Martin et al., 1998; Mester et al., 1998). High copper content in the residual fraction of river sediments was also found by Budimir and Marko (1995). The high proportion of $\mathrm{Cu}$ in this fraction is likely due to that $\mathrm{Cu}$ is chemisorbed on or incorporated in clay minerals (Pickering, 1986). About 20\% of $\mathrm{Zn}$ in average was found in the non-residual fraction in our

Table 4

\begin{tabular}{|c|c|c|c|c|c|}
\hline \multirow[t]{2}{*}{ Element } & \multicolumn{3}{|c|}{ Concentration $\left[\mu \mathrm{g} \mathrm{g}^{-1}\right]$} & \multirow[t]{2}{*}{ Recovery $(1)^{\mathrm{a}}$} & \multirow[t]{2}{*}{ Recovery $(2)^{\mathrm{b}}$} \\
\hline & Sum $^{\mathrm{c}}$ & Total & Reference value & & \\
\hline V & $97.83 \pm 3.21$ & $97.93 \pm 1.23$ & $107.0 \pm 7.0$ & $99.9 \pm 1.7$ & $91.5 \pm 2.2$ \\
\hline $\mathrm{Cr}$ & $113.01 \pm 5.26$ & $134.19 \pm 2.74$ & $136.0 \pm 15.0$ & $84.2 \pm 2.1$ & $98.7 \pm 3.1$ \\
\hline $\mathrm{Mn}$ & $734.65 \pm 19.5$ & $945.23 \pm 8.96$ & $1013.0 \pm 44.0$ & $77.7 \pm 1.9$ & $93.3 \pm 2.4$ \\
\hline $\mathrm{Co}$ & $12.68 \pm 0.58$ & $13.31 \pm 0.30$ & $15.3 \pm 1.7$ & $95.3 \pm 2.7$ & $87.0 \pm 1.9$ \\
\hline $\mathrm{Ni}$ & $27.24 \pm 1.32$ & $28.65 \pm 0.27$ & $30.2 \pm 2.6$ & $95.1 \pm 4.3$ & $94.9 \pm 1.3$ \\
\hline $\mathrm{Cu}$ & $19.24 \pm 0.89$ & $20.13 \pm 0.69$ & $22.6 \pm 2.0$ & $95.6 \pm 3.6$ & $89.1 \pm 2.4$ \\
\hline $\mathrm{Zn}$ & $59.82 \pm 2.74$ & $52.05 \pm 1.53$ & $46.0 \pm 5.0$ & $114.9 \pm 2.8$ & $113.2 \pm 4.2$ \\
\hline Mo & $1.44 \pm 0.06$ & $1.45 \pm 0.03$ & $1.2 \pm 0.2$ & $99.3 \pm 3.1$ & $121.0 \pm 3.7$ \\
\hline $\mathrm{Cd}$ & $0.99 \pm 0.05$ & $1.05 \pm 0.03$ & $1.12 \pm 0.12$ & $94.7 \pm 1.9$ & $93.4 \pm 1.5$ \\
\hline $\mathrm{Sn}$ & $1.93 \pm 0.12$ & $1.66 \pm 0.08$ & $1.4 \pm 0.4$ & $116.7 \pm 3.6$ & $118.3 \pm 4.1$ \\
\hline $\mathrm{Pb}$ & $25.54 \pm 0.41$ & $28.98 \pm 0.19$ & $27.0 \pm 3.0$ & $88.1 \pm 2.1$ & $107.3 \pm 2.7$ \\
\hline
\end{tabular}

Recovery of the sequential extraction and the total digestion $(n=5)$

\footnotetext{
${ }^{\text {a }}$ Recovery (1): Sum/Total.

${ }^{\mathrm{b}}$ Recovery (2): Total/Reference value.

${ }^{\mathrm{c}} \mathrm{Sum}=$ fraction $\mathrm{A}+$ fraction $\mathrm{B}+$ fraction $\mathrm{C}+$ fraction $\mathrm{D}$.
} 

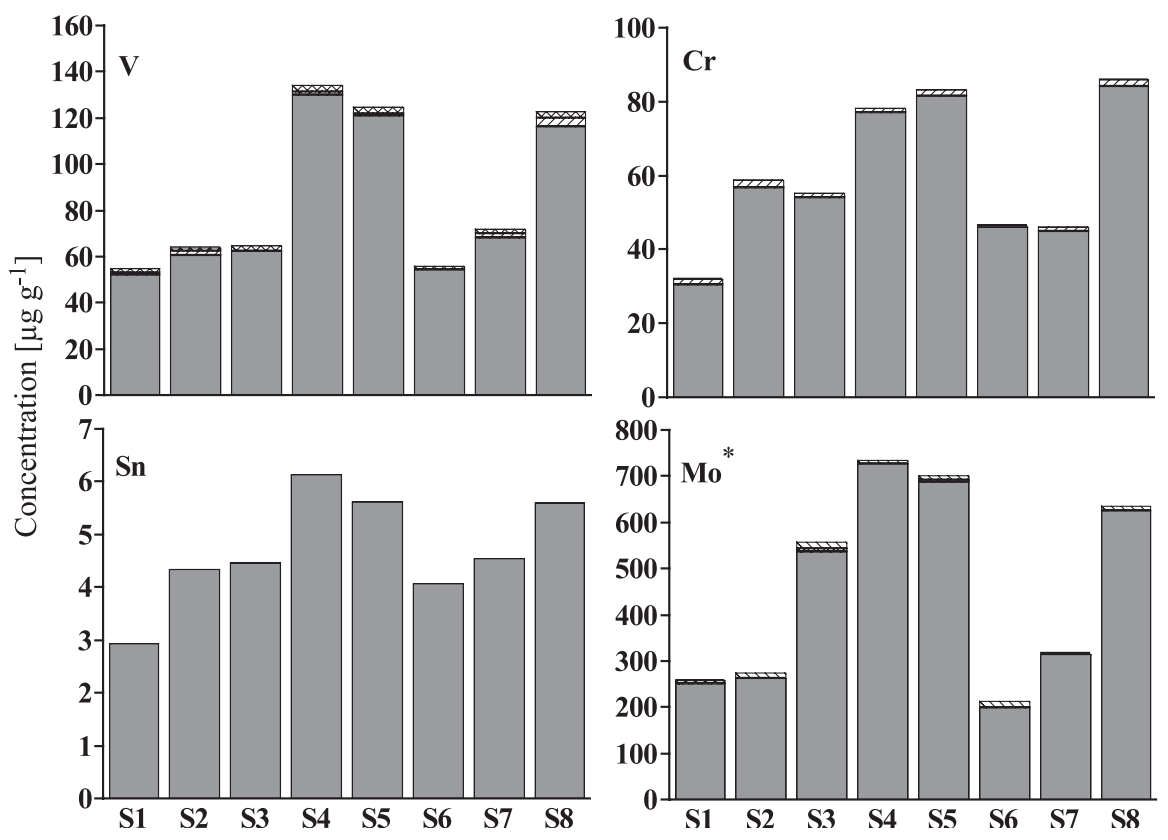

Fig. 2. Distribution of V, Cr, Sn and Mo in top sediments from the East China Sea. $\square$, Fraction A; $区$, Fraction B; $\square Z$, Fraction C; $\square$, Fraction D. *units $\mathrm{ng} \mathrm{g}^{-1}$.

study. This was far lower than $40 \%$ reported by Usero et al. (1998).

\subsubsection{Iron and manganese}

The results of $\mathrm{Fe}$ and $\mathrm{Mn}$ are illustrated in Fig. 4. A negligible amount of $\mathrm{Fe}$ was found in the acid soluble fraction compared to the total concentration. The dominant proportion (ca. 90\%) of Fe was in the residual fraction. This result was in good agreement with the data reported by Usero et al. (1998) who found that more than $89 \%$ of the total $\mathrm{Fe}$ was in the residual fraction. The distribution patterns of $\mathrm{Fe}$ at eight sampling sites were similar.

Unlike $\mathrm{Fe}$, a considerable proportion of $\mathrm{Mn}$ was found in all of the four fractions, as observed by other researchers (Usero et al., 1998; Ngiam and Lim, 2001). A significant amount of Mn was found in the acid soluble fraction. In this
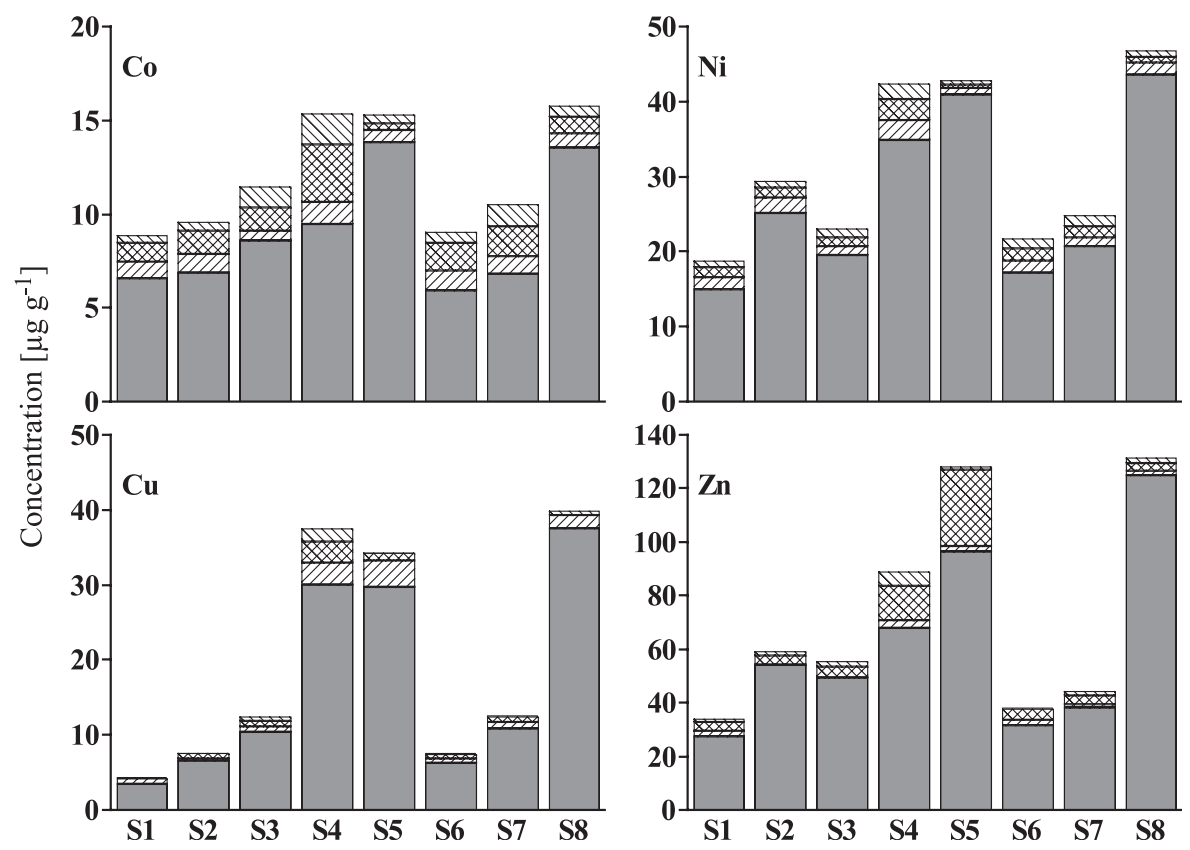

Fig. 3. Distribution of $\mathrm{Co}, \mathrm{Ni}, \mathrm{Cu}$ and $\mathrm{Zn}$ in top sediments from the East China Sea. $\square$, Fraction A; 区X, Fraction B; $\square Z$, Fraction C; $\square$, Fraction D. 

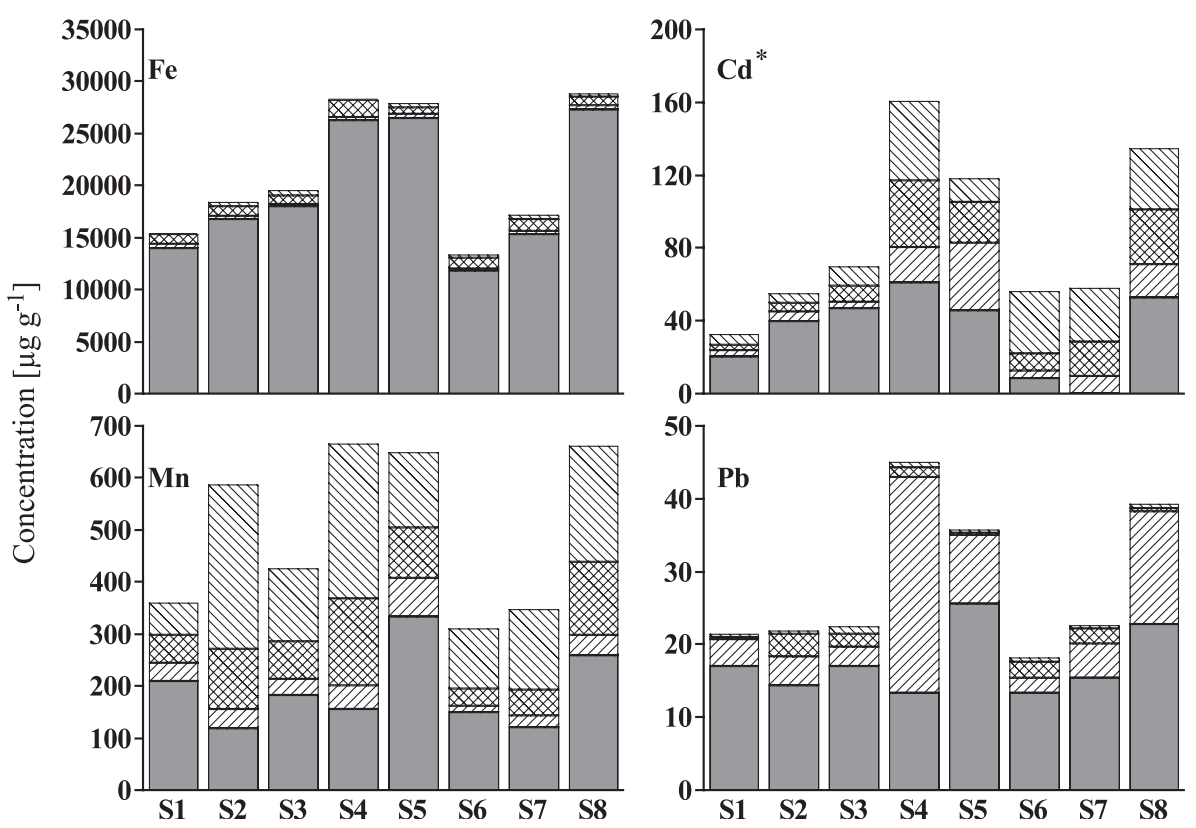

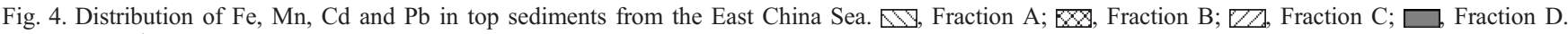

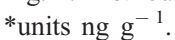

fraction, weakly sorbed Mn retained on sediment surface by relatively weak electrostatic interactions may be released by ion-exchange processes and dissociation of Mn-carbonate phase (Tessier et al., 1979). The result indicates that considerable amount of Mn may be released into environment if conditions become more acidic (Thomas et al., 1994). In addition, a considerable amount of Mn was detected in the reducible fraction, in which Mn exists as oxides and may be released if the sediment is subjected to more reducing conditions (Panda et al., 1995).

\subsubsection{Cadmium and lead}

Much concern has been focused on the levels of $\mathrm{Cd}$ and $\mathrm{Pb}$ in sediments for long time because of their high toxicity. Several sequential extraction procedures, including the BCR protocol, have been used to obtain information of the distribution of $\mathrm{Cd}$ and $\mathrm{Pb}$ in sediment (Zdenek, 1996; Serife et al., 2000; Ngiam and Lim, 2001). Not only sediments but also other samples, such as soil (Stalikas et al., 1999) and fly ash samples (Ildiko et al., 1996) have been determined for the concentrations of $\mathrm{Cd}$ and $\mathrm{Pb}$ phase distribution by sequential extraction methods. In this work, the two toxic heavy metals were also detected in the marine sediments after the BCR sequential extraction.

The results of sequential extraction for $\mathrm{Cd}$ and $\mathrm{Pb}$ are illustrated in Fig. 4. The dominant proportion (60.4\%) of Cd was found in the exchangeable and the acid soluble fraction at S6, which indicates that most of $\mathrm{Cd}$ in the selected sediments is exchangeable and bound to carbonates. The trace metals in this fraction are adsorbed on sediments or on their essential components namely clays, $\mathrm{Fe}$ and $\mathrm{Mn}$ hydrated oxides, and humic acids. The adsorption of trace metals is related to changes in water ionic strength that probably affect sorption-desorption processes (Tessier et al., 1979), and it is known that the carbonates in sediment contain significant trace metal concentrations, which are sensitive to changes in $\mathrm{pH}$ (Thomas et al., 1994). The $\mathrm{Cd}$ in this fraction is the most labile, hence, it may be available for uptake by the total biota. Higher concentration of metals in

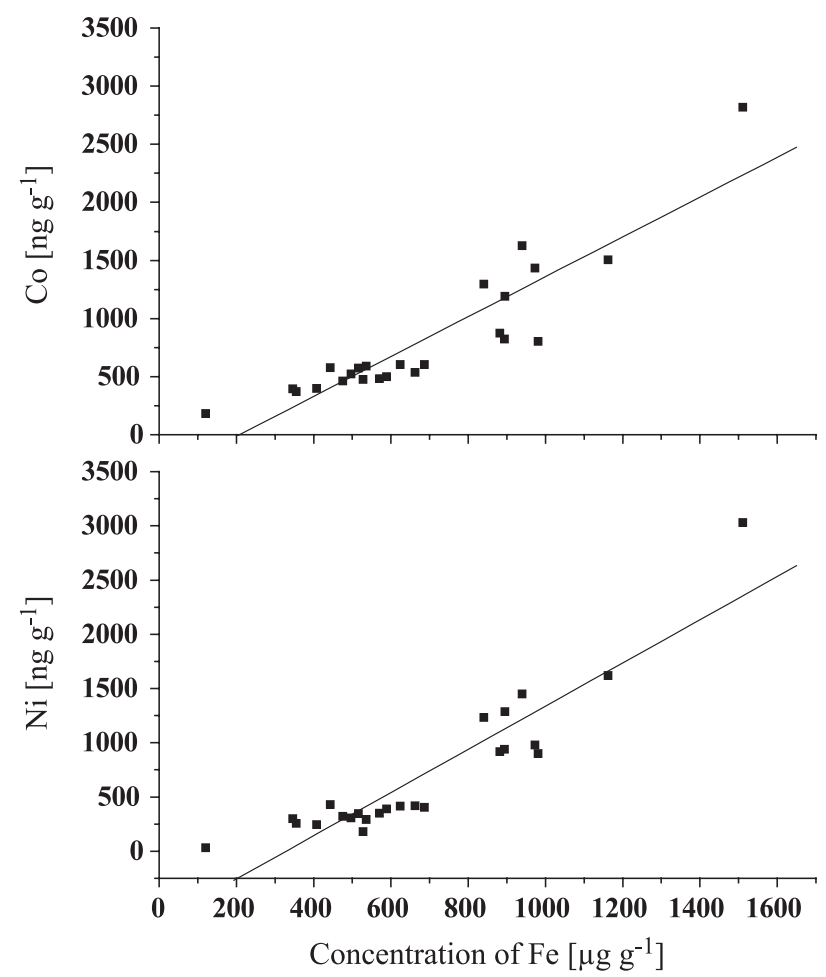

Fig. 5. Correlations between $\mathrm{Fe}, \mathrm{Co}$ and $\mathrm{Ni}$ in fraction $\mathrm{B}\left(r_{\mathrm{Fe}-\mathrm{Co}}=0.92\right.$, $r_{\mathrm{Fe}-\mathrm{Ni}}=0.91$ ). 
this fraction could be regarded as a pollution indicator (Forstner et al., 1979).

The distributions of $\mathrm{Cd}$ differed significantly with the sampling site. Almost all of Cd (99\% of the total Cd) was found in the non-residual fraction at site S7. However, only $27 \%$ of the total concentration of $\mathrm{Cd}$ was found at $\mathrm{S} 1$, where the concentration of $\mathrm{Cd}$ in the non-residual fraction was the lowest. Sites S4, S5, S6, S7 and S8 were found with higher concentration of $\mathrm{Cd}$ than that at $\mathrm{S} 3$ and $\mathrm{S} 2$. Among all of the sampling sites, S1 was the only one that had the lowest concentration in the non-residual fraction. Evidently the pollution of Cd was mainly from the rivers (Yangtze River and Qiantang River), since the sites (S4, S5, and S8) with higher concentration of $\mathrm{Cd}$ are close to these rivers and all of them are at the flow directions of these two rivers, especially from Qiantang River, in which high concentration of $\mathrm{Cd}(0.72 \mathrm{ppm})$ was found in suspension at the river mouth (Che et al., 2002). In addition, S8 is very close to Ningbo seaport where a lot of waste is produced and discharged every day. With regard to $\mathrm{Pb}$, although the acid soluble proportion was small, the sum concentration of the non-residual fractions was significant. Especially at S4, 70\% of the total $\mathrm{Pb}$ was in the non-residual fractions and $66 \%$ was found in the oxidable fraction. The distribution pattern of $\mathrm{Pb}$ at $\mathrm{S} 4$ may be explained by that the metal $\mathrm{Pb}$ is mostly bound to the organic matter and sulfides. The metals in this fraction may be released into environment if conditions become more oxidising.

The planar distribution of the metals indicated the high pollutions (especially $\mathrm{Cd}$ and $\mathrm{Pb}$ ) at $\mathrm{S} 4$ and $\mathrm{S} 8$. Both the

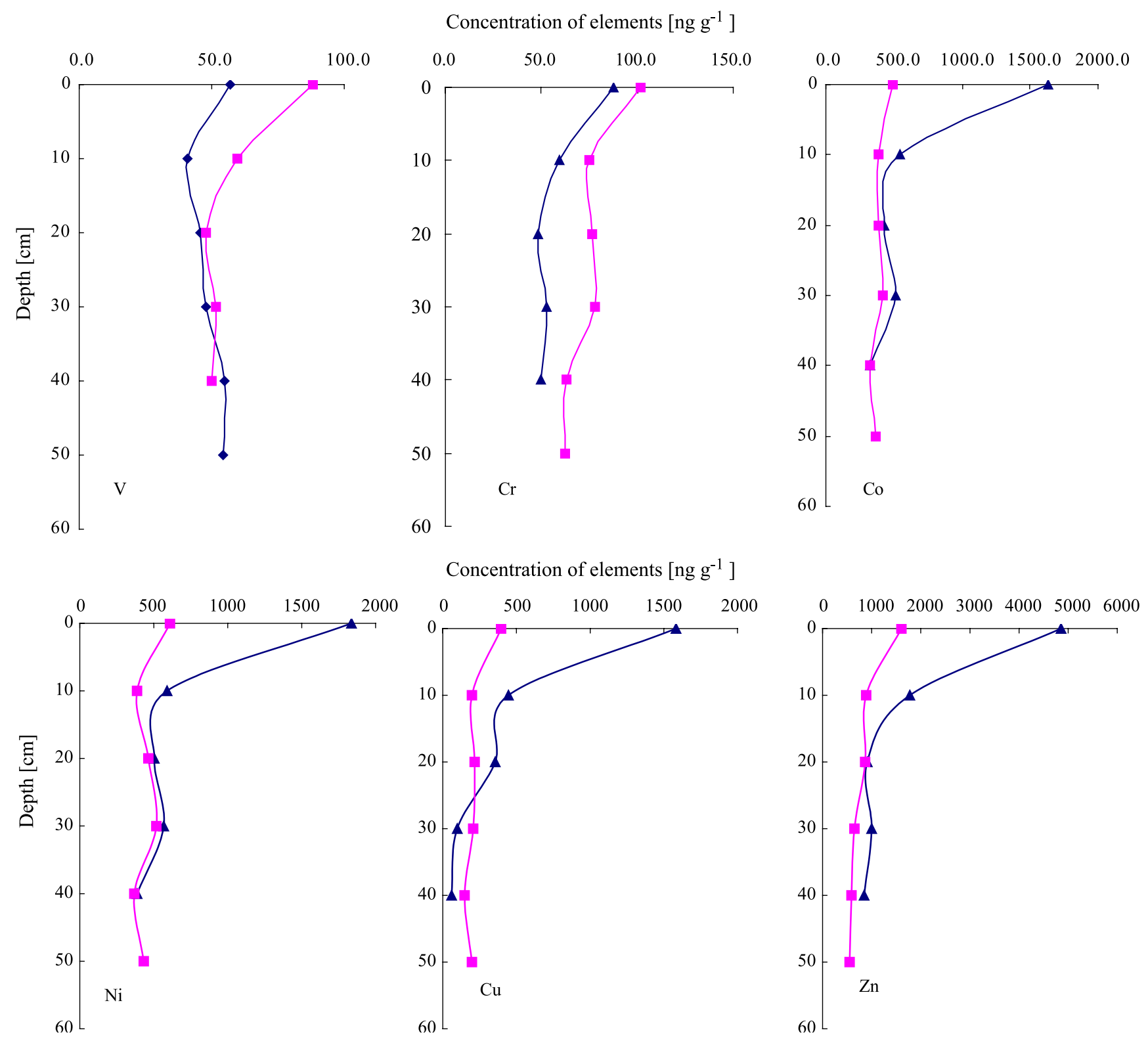

Fig. 6. Concentration variation of elements in fraction A with depth. $\Delta$ Site 4 , $\mathbf{a}$ Site 8 . 


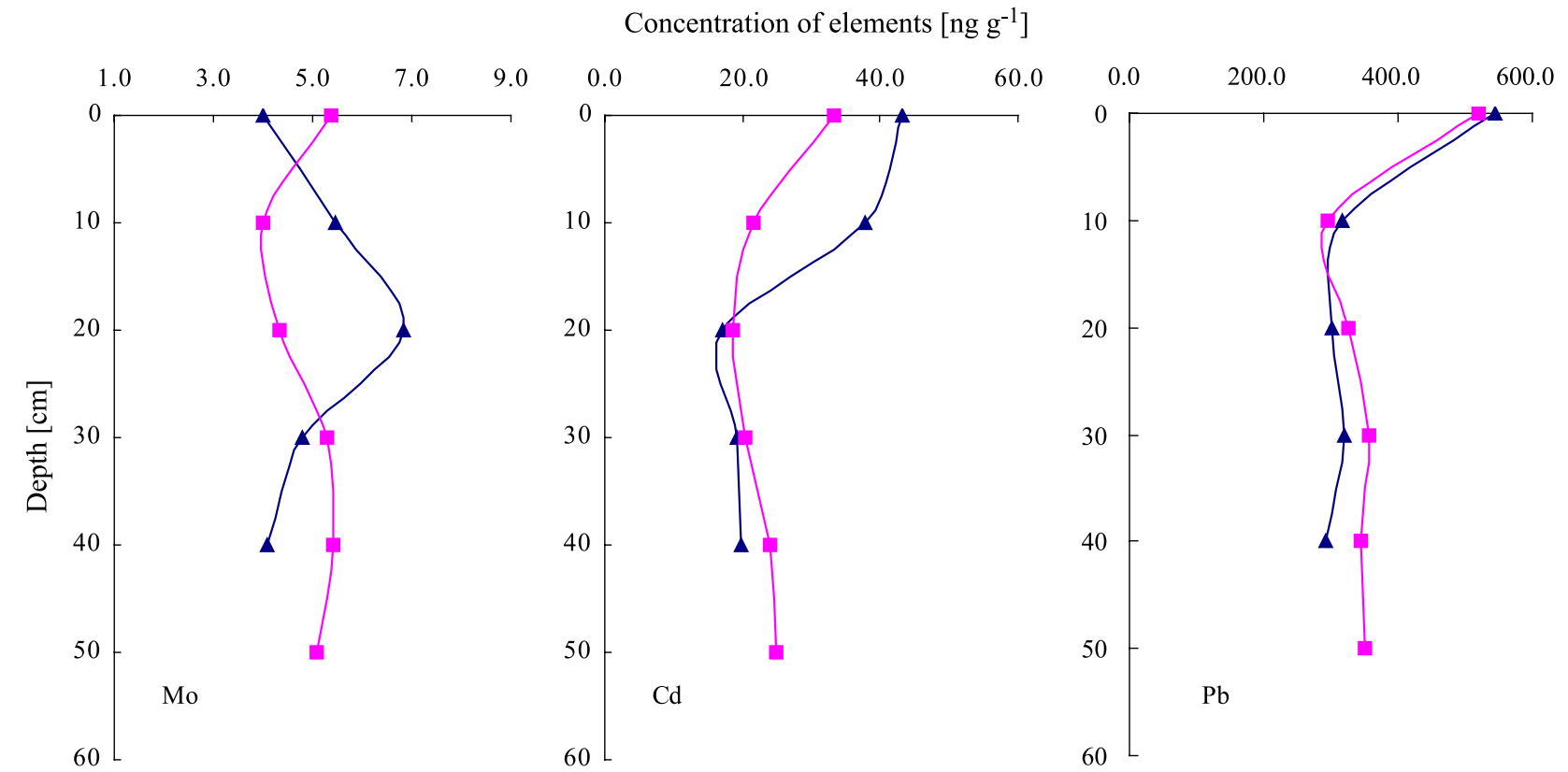

Concentration of elements $\left[\mu \mathrm{g} \mathrm{g}^{-1}\right]$
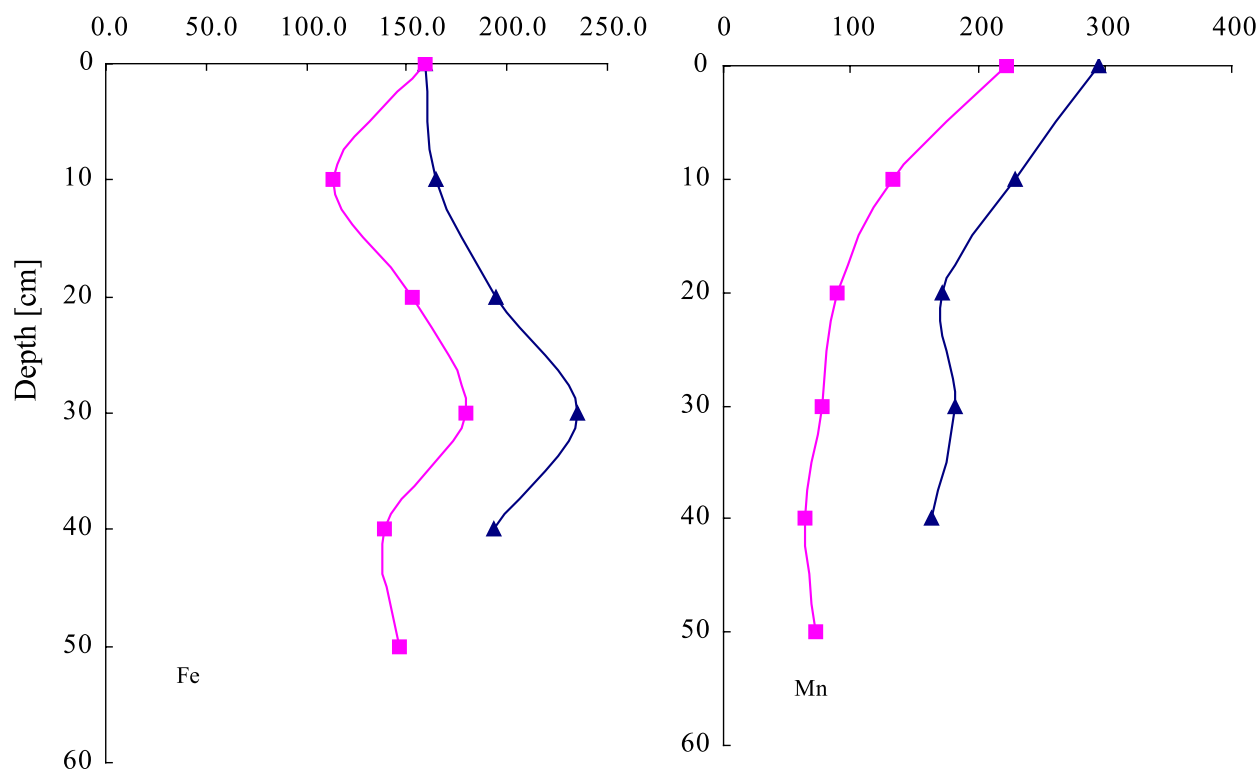

Fig. 6 (continued).

total concentration and the non-residual fractions of $\mathrm{Cd}$ and $\mathrm{Pb}$ in the sediments were found high at S4 and S8 (Figs. 24). The distribution of elements at S1, far from the land and affected slightly by human actives, was chosen as a background to compare with that at S4 and S8. Our results just verified the assumption that the sampling sites S4 and S8 were thought to be at the risk of being polluted heavily.

\subsection{Correlation factor investigation}

To evaluate the effects of TOC and $\mathrm{Fe}-\mathrm{Mn}$ on the element distributions in the selected sediments, correlation investigation was performed in this study.

\subsubsection{Effect of TOC and $p H$ on element distribution}

The contents of the total organic carbon in the selected sediment samples were determined to investigate the relationship between the phase distributions of elements and TOC content. For the fraction $\mathrm{C}$, the distributions of $\mathrm{Pb}$ $(r=0.54, P<0.01), \mathrm{Cd}(r=0.57, P<0.01)$ and $\mathrm{Cu}(r=0.65$, $P<0.01)$ were correlated with the content of TOC.

The results of this investigation could not give any evident proof on correlations between the fraction A and TOC for all of the elements. Similar results could be concluded for metals in fraction B except for $\mathrm{V}(r=0.65, P<0.01)$ and $\mathrm{Cd}(r=0.51$, $P<0.01)$, which indicates that in fraction $\mathrm{B}$ the distributions of $\mathrm{V}$ and $\mathrm{Cd}$ may be affected by TOC. 
The $\mathrm{pH}$ values of sediments were determined but no evident variation among different sampling sites had been found, so the effect of $\mathrm{pH}$ on the distribution of elements in the real sample analysis was not obvious.

\subsection{2. $\mathrm{Fe}-\mathrm{Mn}$ effect on the distribution of metal speciation}

High correlations between the total amount of $\mathrm{Fe}-\mathrm{Mn}$ and the concentration of $\mathrm{V}$ and $\mathrm{Cd}$ in the fraction $\mathrm{B}$ were found in this study. The correlation coefficients between them were $0.81(P<0.01)$ and $0.66(P<0.01)$ for $\mathrm{V}$ and $\mathrm{Cd}$, respectively. As to the fraction $\mathrm{C}$, the concentrations of $\mathrm{Cu}(r=0.70), \mathrm{Pb}(r=0.68)$ and $\mathrm{Cr}(r=0.63)$ were in good correlations with the total amount of $\mathrm{Fe}-\mathrm{Mn}$. This result indicates that the distribution of $\mathrm{V}$ and $\mathrm{Cd}$ in the fraction $\mathrm{B}$ and $\mathrm{Cu}, \mathrm{Pb}$ and $\mathrm{Cr}$ in the fraction $\mathrm{C}$ were influenced by
$\mathrm{Fe}-\mathrm{Mn}$ greatly. As to other elements in the fractions $\mathrm{B}$ and $\mathrm{C}$, no evident correlation between them was found, and there was little correlation between the amount of $\mathrm{Fe}-\mathrm{Mn}$ and the metal concentrations in the fraction $\mathrm{A}$ for all of the elements.

\subsubsection{Correlations between $\mathrm{Fe}, \mathrm{Co}$ and $\mathrm{Ni}$}

It was found that there were high correlations between $\mathrm{Fe}, \mathrm{Co}$ and $\mathrm{Ni}$ in the fraction $\mathrm{B}\left(r_{\mathrm{Fe}-\mathrm{Co}}=0.92, r_{\mathrm{Fe}-\mathrm{Ni}}=\right.$ 0.91). Similar correlations were not found in other fractions. The high correlations between $\mathrm{Fe}, \mathrm{Co}$ and $\mathrm{Ni}$ in fraction $\mathrm{B}$ could be interpreted by the high correlations of the total concentrations $\left(r_{\mathrm{Fe}-\mathrm{Co}}=0.96, r_{\mathrm{Fe}-\mathrm{Ni}}=0.96\right)$. The correlations between $\mathrm{Fe}, \mathrm{Co}$ and $\mathrm{Ni}$ in fraction $\mathrm{B}$ are shown in Fig. 5.

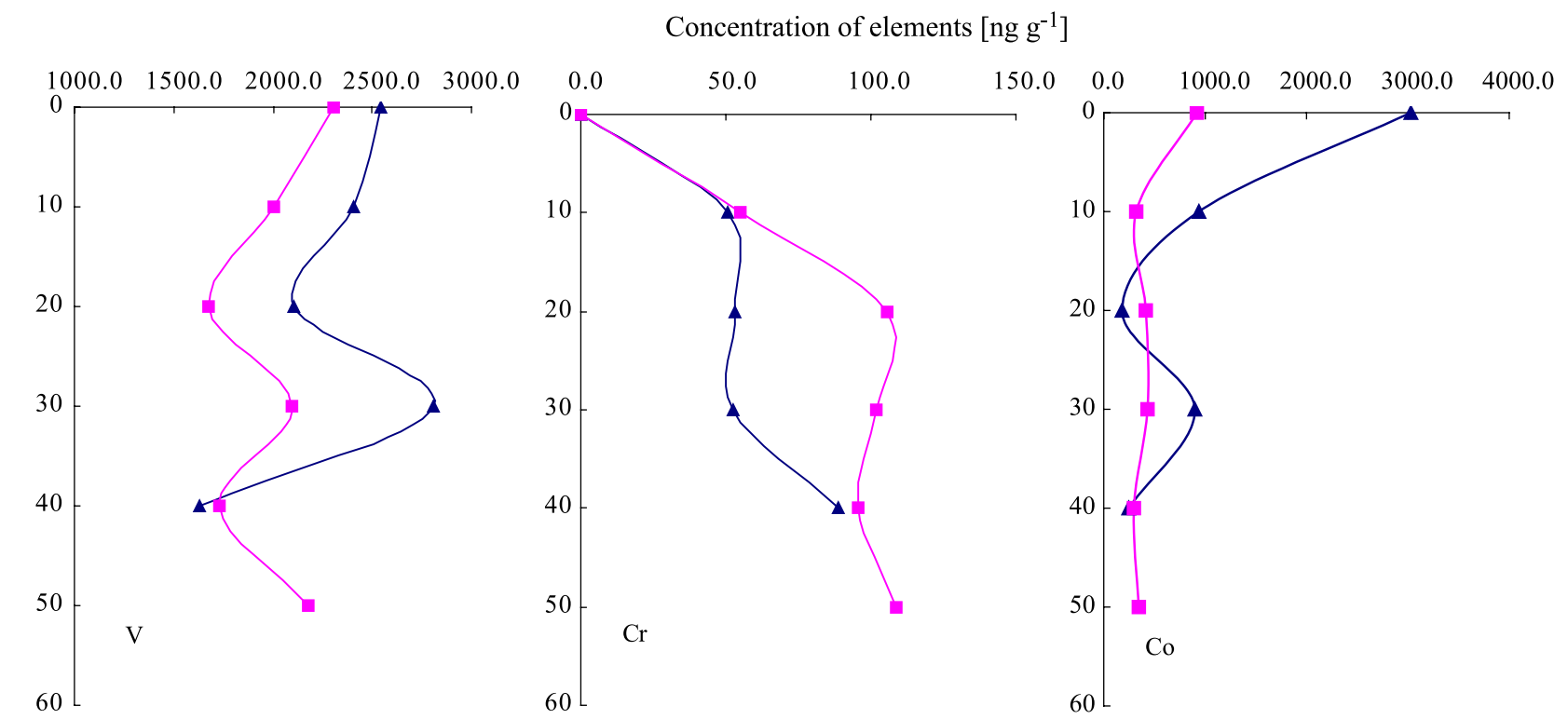

Concentration of elements [ng g $\left.{ }^{-1}\right]$
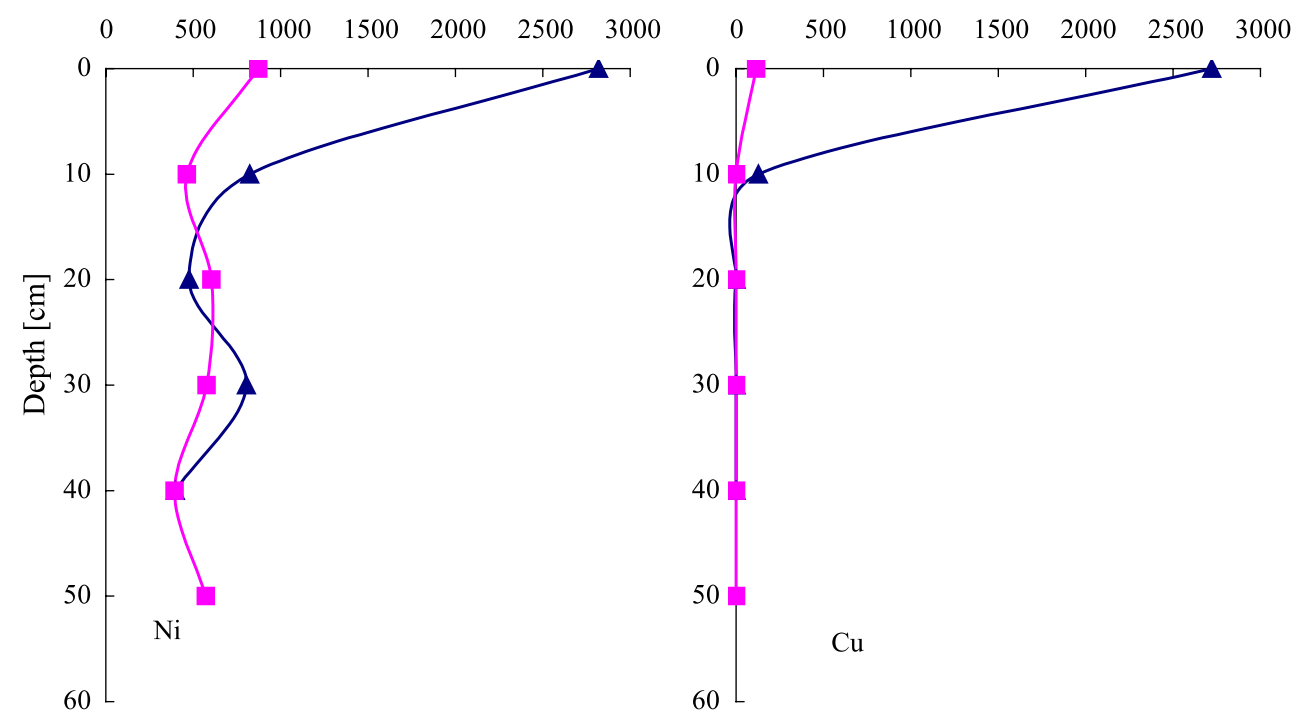

Fig. 7. Concentration variation of elements in fraction B with depth. $\Delta$ Site 4 , $\mathbf{\square}$ Site 8 . 


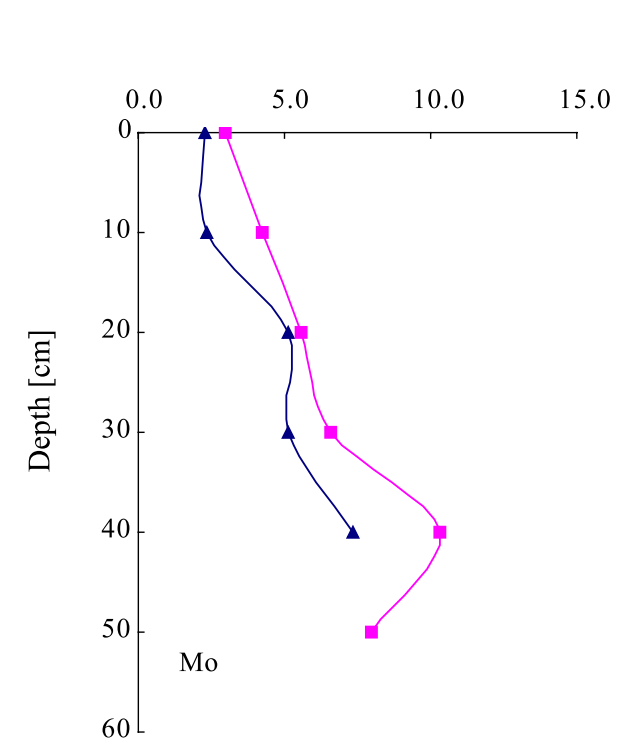

Concentration of elements [ng g ${ }^{-1}$ ]
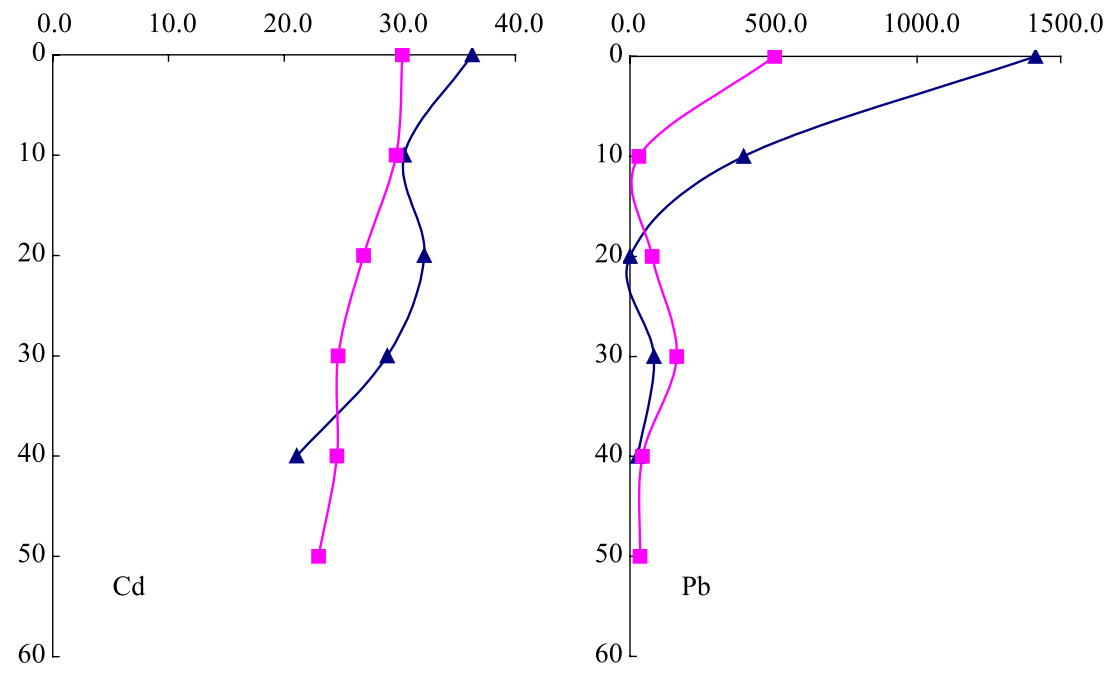

Concentration of elements $\left[\mu \mathrm{g} \mathrm{g}^{-1}\right]$
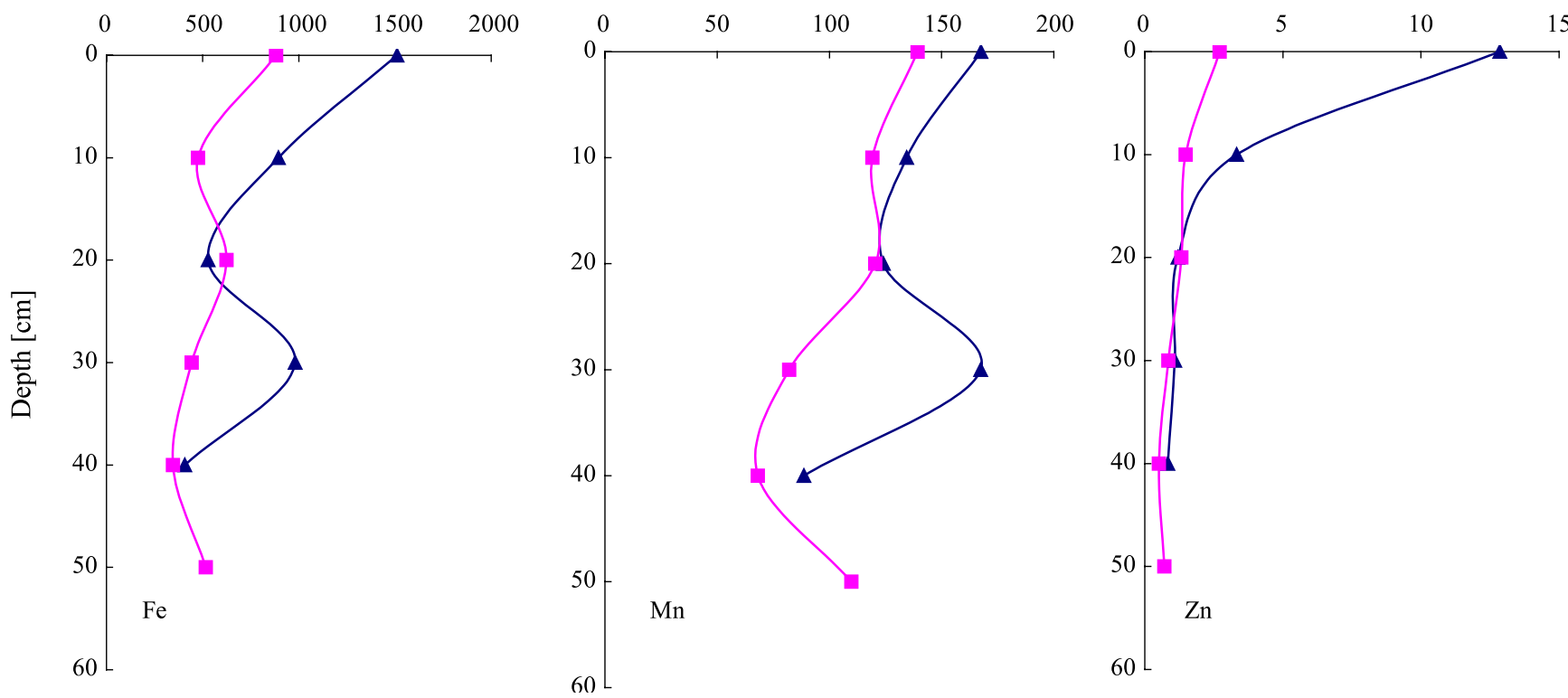

Fig. 7 (continued).

\subsection{Variation of metal distribution patterns with depth}

To investigate variation of distribution patterns of metals in the non-residual fractions with depth, two sediment cores (with length of 40 and $50 \mathrm{~cm}$, respectively) were collected at S4 and S8. The reason for choosing these two sites for this study is that these two sites are close to the land and may be more polluted than the others.

\subsubsection{Fraction A}

The variation of element concentration in fraction A with depth at S4 and S8 is shown in Fig. 6. The concentrations of metals in the top sediments were the highest compared to other depth subsamples for most of the elements at the two sampling sites except for Fe at S4 and Mo at S8. Variation trends of concentration for each element in the two sample cores were similar. The surface enrichment may be due to contamination deposited from the surface waters, which also indicates that the pollutions are posed in the recent years. This is because the pollution is always absorbed into top sediment at first, and then sinks into more deep positions by chemical exchange. At the same time, reductive dissolution of $\mathrm{Fe}-\mathrm{Mn}$ oxides at depth may also result in the release of any sorbed heavy metals.

The fact that much higher concentrations of $\mathrm{Co}$, Ni, $\mathrm{Cu}$ and $\mathrm{Zn}$ in the fraction $\mathrm{A}$ in the top sediments were found at S4 than that at S8 indicates that S4 suffered more heavily pollution from these elements than S8. The 
discrimination became small with the deepening of depth, especially when the depth was deeper than $20 \mathrm{~cm}$. This phenomenon may be interpreted by that the elements in the fraction A were mainly caused by pollution in the top sediments. With the deepening of depth, the effects of pollution become slighter and the distribution of elements mainly depends on the sediments themselves geographically.

\subsubsection{Fraction $B$}

The concentration variation of elements in the fraction B with depth at S4 and S8 is shown in Fig. 7. Higher concentrations were found in the top sediments for most of elements except for Mo and Cr. It should be highlighted that much higher concentration of $\mathrm{Co}, \mathrm{Cu}, \mathrm{Ni}$ and $\mathrm{Zn}$ was found in the top sediments at S4 than that at S8. Only 128.2 and $114.2 \mathrm{ng}$ $\mathrm{g}^{-1} \mathrm{Cu}$ were detected in this fraction in the top sediments at $\mathrm{S} 4$ and $\mathrm{S} 8$, respectively. At deeper positions, $\mathrm{Cu}$ in the fraction B could not be detected. The results show that larger amount of elements may be sorbed by more $\mathrm{Fe}-\mathrm{Mn}$ oxides in the top sediments than at the deeper positions. That could be interpreted by that the reductive dissolution of $\mathrm{Fe}-\mathrm{Mn}$ oxides will occur at deeper position in the absence of significant sulphide which could fix the Fe and $\mathrm{Mn}$ as sulphide phase followed by precipitation upon crossing the oxic/anoxic boundary. The freshly formed $\mathrm{Fe}-\mathrm{Mn}$ oxides may also scavenge a significant amount of upwards diffusing heavy metals.

For $\mathrm{Cr}$ and $\mathrm{Mo}$, the variation trends were not similar to that of the other elements. Cr was not detected in this fraction in the top sediments at both sampling sites S4 and S8. Only small amount of Mo (3.0 and $2.3 \mathrm{ng} \mathrm{g}^{-1}$ for S8 and S4, respectively) was detected in the top sediments. The concentration of $\mathrm{Cr}$ increased with depth from the top to the $20-\mathrm{cm}$ position and kept good linearity at S8. Similar result as that for $\mathrm{Cr}$ was concluded for Mo at S8 and S4.

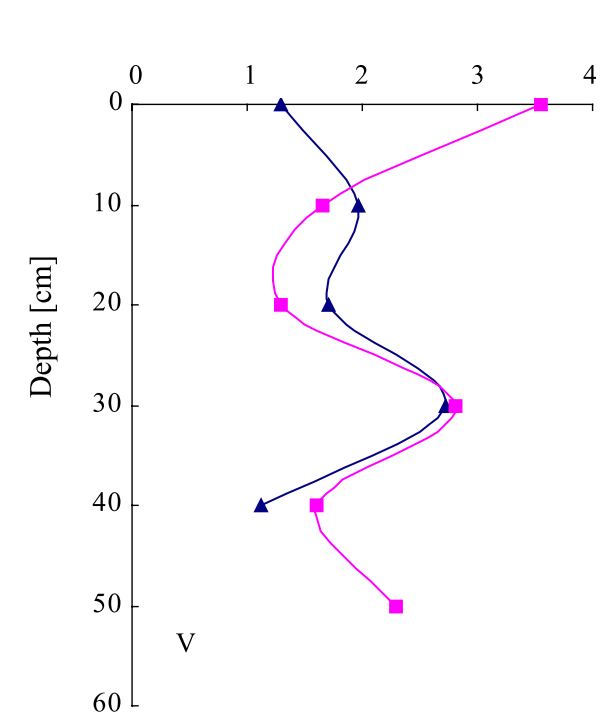

\section{Concentration of elements $\left[\mu \mathrm{g} \mathrm{g}^{-1}\right]$}
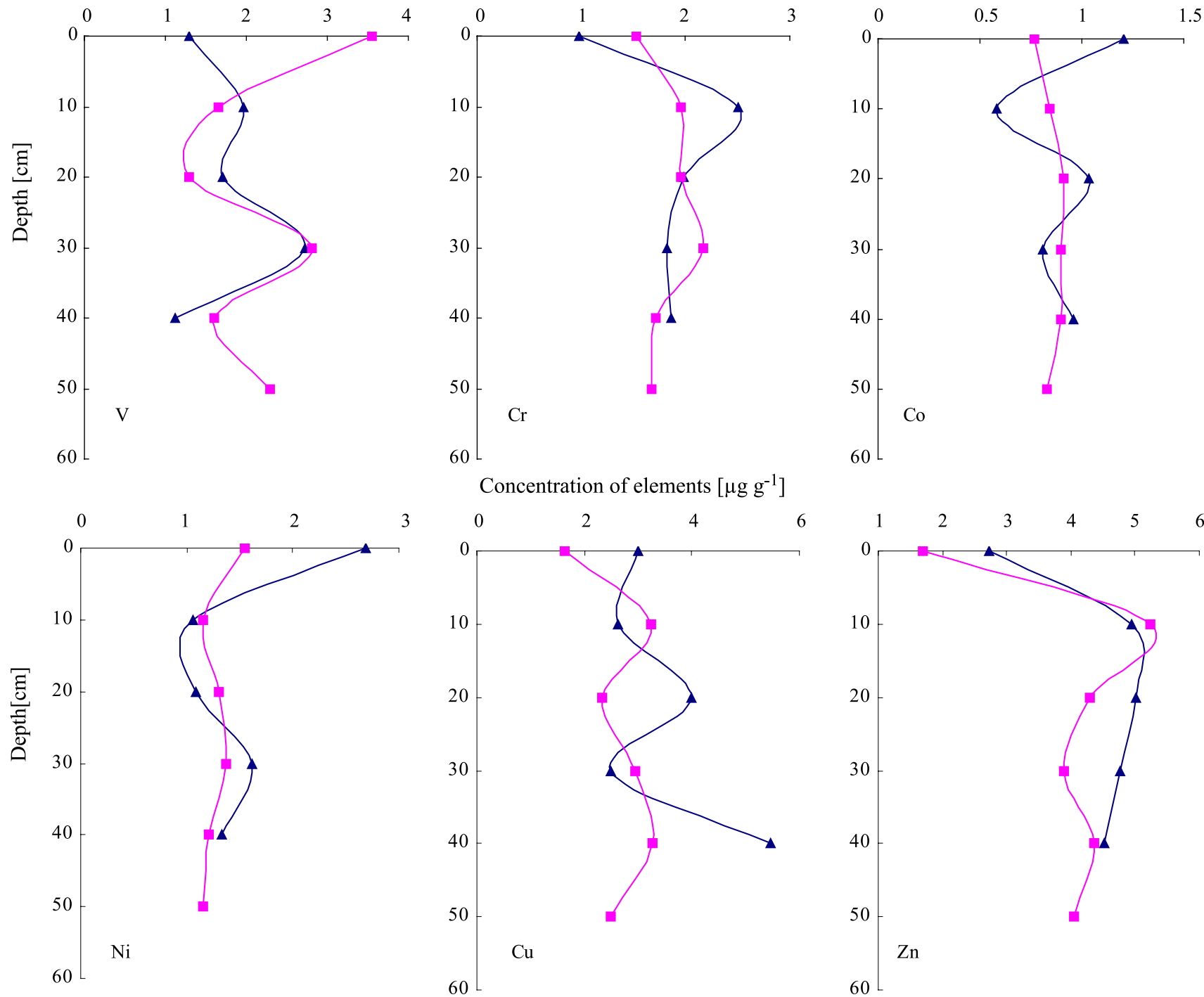

Concentration of elements $\left[\mu \mathrm{g} \mathrm{g}^{-1}\right]$
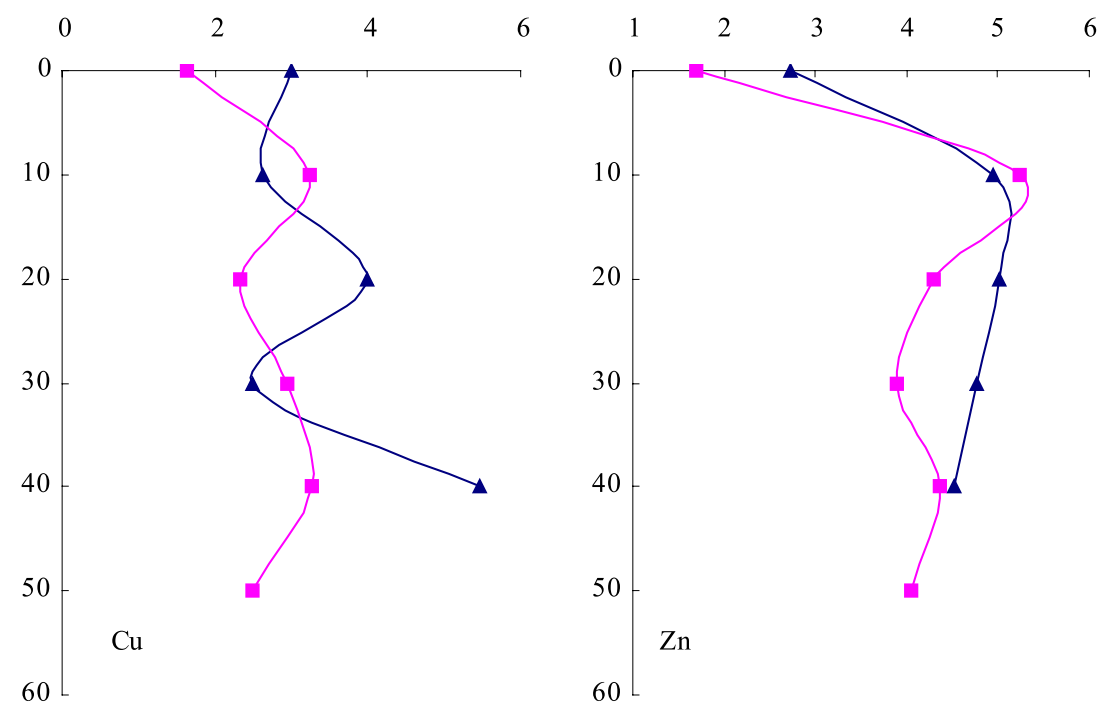

Fig. 8. Concentration variation of elements in fraction C with depth. $\Delta$ Site 4 , $\mathbf{a}$ Site 8. 

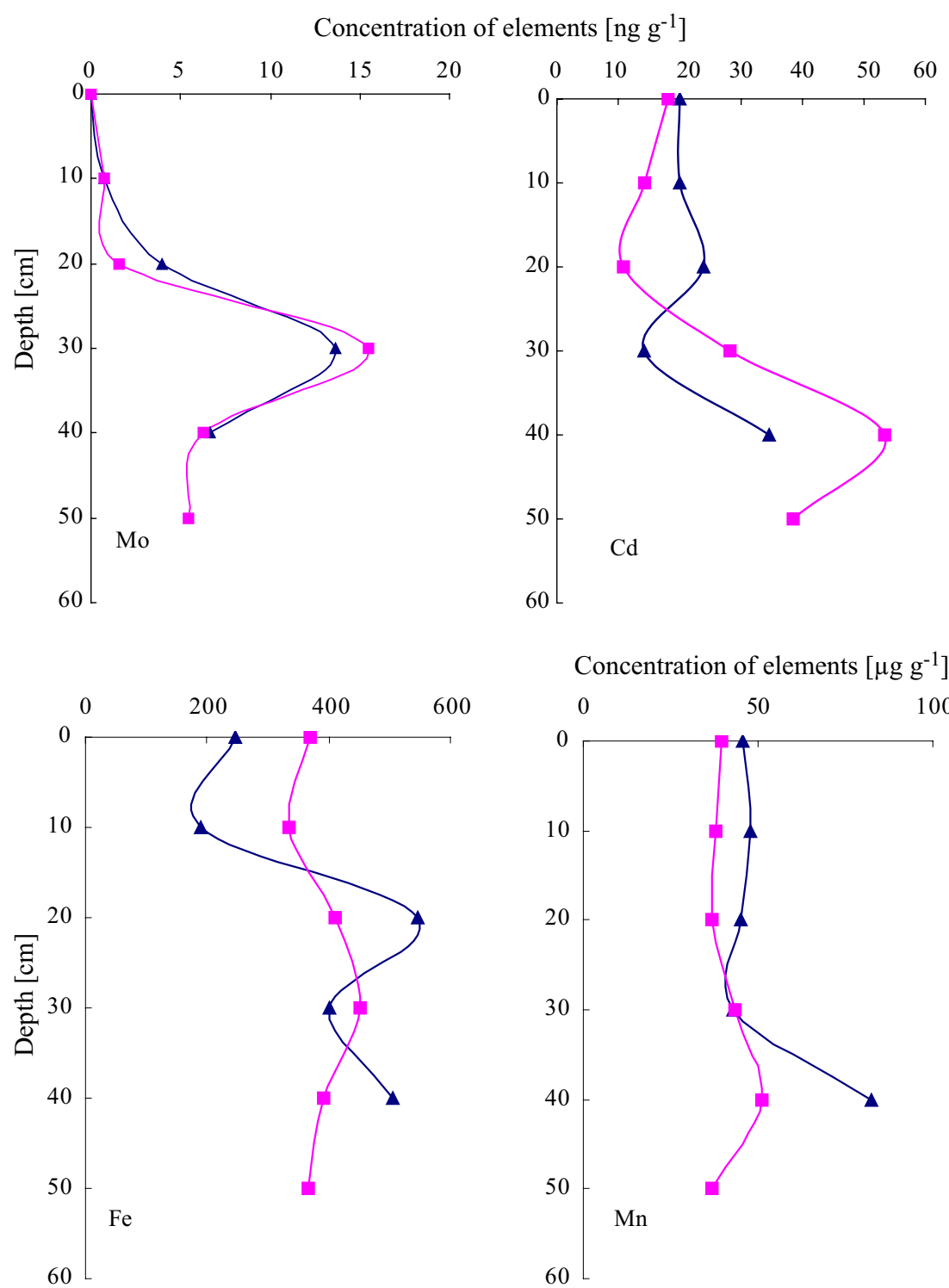

Concentration of elements $\left[\mu \mathrm{g} \mathrm{g}^{-1}\right]$

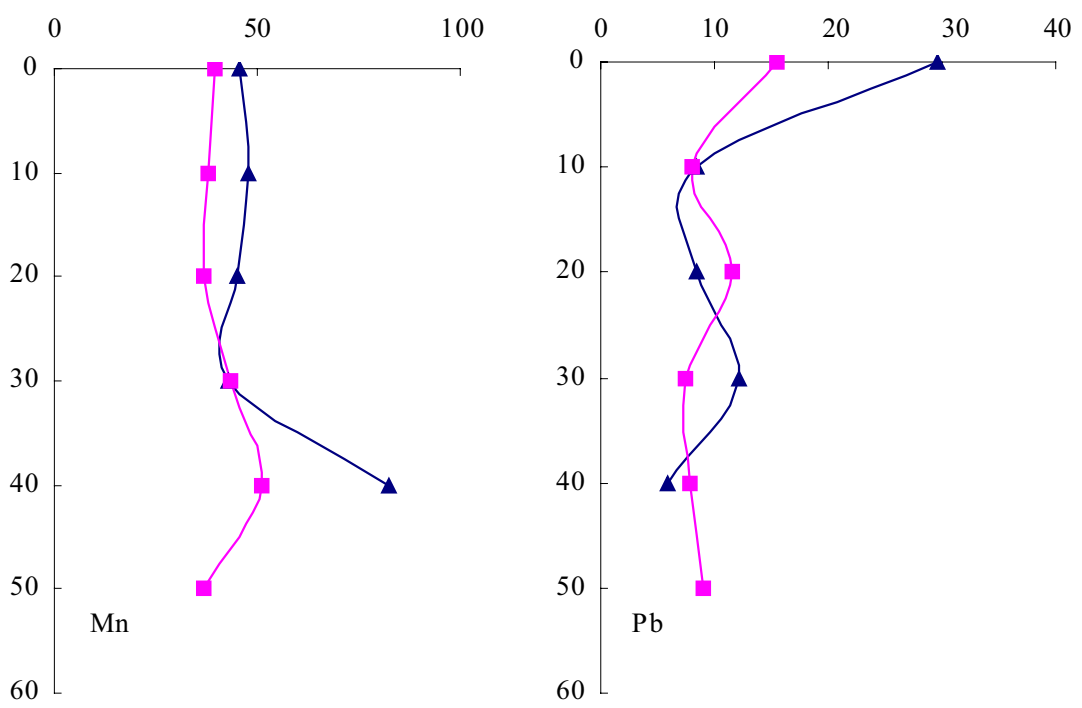

Fig. 8 (continued).

\subsubsection{Fraction $C$}

The variation of element concentration in the fraction $\mathrm{C}$ with depth at S4 and S8 is shown in Fig. 8. The variation of the concentrations of elements in this fraction was more complex than the other two fractions. There was no evident rule that could be concluded from the results, but some useful information could be obtained. In both sampling sites, the concentration of $\mathrm{Zn}$ increased immediately from the top (ca. 2 $\mu \mathrm{g} \mathrm{g}^{-1}$ ) to the 10 -cm depth (ca. $5 \mu \mathrm{g} \mathrm{g}^{-1}$ ) and then decreased to about $4.0 \mu \mathrm{g} \mathrm{g}^{-1}$ gently. The variation trends of $\mathrm{Fe}$ and $\mathrm{Mn}$ at site $\mathrm{S} 4$ were similar to that at $\mathrm{S} 8$. The concentrations of $\mathrm{Pb}$, $\mathrm{Co}$ and Ni decreased with the depth. As for $\mathrm{Cd}$ and $\mathrm{Mn}$, the variation was similar at $\mathrm{S} 4$ and $\mathrm{S} 8$. Elements in the fraction $\mathrm{C}$ mainly bound to various forms of organic matter by complexation and peptization properties of natural organic matter or bioaccumulation in certain living organisms through different ways. So the variation of the elements in this fraction became more complex and irregular than that in the fractions $\mathrm{A}$ and $\mathrm{B}$.

\section{Conclusions}

The BCR sequential extraction method has been applied to the analysis of the metal distributions in the sediments from the East China Sea successfully and the results yielded the information as below:

(1) V, Cr, Mo and Sn were found dominantly in the residual fraction in the studied region. The other elements were found in all of the fractions with the different proportions. The significant proportion of the total concentration (for $\mathrm{Fe}, \mathrm{Co}, \mathrm{Ni}, \mathrm{Cu}$, and $\mathrm{Zn}$ ) was also in the residual fraction. The dominant proportion was 
found in the non-residual fractions for $\mathrm{Mn}$ and $\mathrm{Cd}$. As to $\mathrm{Pb}$, the sum concentration of the non-residual fractions was significant.

(2) The distributions of $\mathrm{Pb}, \mathrm{Cd}$ and $\mathrm{Cu}$ in fraction $\mathrm{C}$, and $\mathrm{V}$ and $\mathrm{Cd}$ in fraction $\mathrm{B}$ were correlated with TOC. High correlations were also found between the total amount of $\mathrm{Fe}-\mathrm{Mn}$ and the concentration of $\mathrm{V}$ and $\mathrm{Cd}$ in fraction $\mathrm{B}$. In addition, high correlations were found between $\mathrm{Fe}$, $\mathrm{Co}$ and $\mathrm{Ni}$ in fraction $\mathrm{B}\left(r_{\mathrm{Fe}-\mathrm{Co}}=0.92, r_{\mathrm{Fe}-\mathrm{Ni}}=0.91\right.$, $\left.r_{\mathrm{Co}-\mathrm{Ni}}=0.98\right)$.

(3) The distribution variation with depth showed that element concentration in the fraction $\mathrm{A} / \mathrm{B}$ was higher in the top sediments than that in the deeper positions for most of the elements. The evident difference between the concentration of elements $\mathrm{Co}, \mathrm{Cu}, \mathrm{Ni}$ and $\mathrm{Zn}$ in the fraction $\mathrm{A} / \mathrm{B}$ in the top sediments at $\mathrm{S} 4$ and $\mathrm{S} 8$ indicated that $\mathrm{S} 4$ was polluted more seriously than S8. Since the anthropogenic effects on distribution of elements became slight at deeper positions, the difference between the two sites became smaller. For the fraction $\mathrm{C}$, the variation seemed more complex and irregular for complex ways through which elements in this fraction formed.

(4) Overall, the planar distribution of metals indicated that S4 and S8 were more severely polluted than other sampling sites by heavy metals, especially by $\mathrm{Cd}$ and $\mathrm{Pb}$. Interventions should be made to reduce anthropogenic discharges in this region.

\section{Acknowledgements}

This work was jointly supported by National Natural Science Foundation of China $(20137010,20205008)$ and Chinese Academy of Sciences (KZCX2-414). The authors are indebted to Dr. Ming-jiang Zhou (National Ocean Bureau, China) and all of the workers on the ship of Science No. 1 for sampling the marine sediments.

\section{References}

Agnieszka S, Wieslaw Z. Application of sequential extraction and the ICPAES method for study of the partitioning of metals in fly ashes. Microchemical Journal 2002;72:9-16.

Borovec Z, Tolar V, Mraz L. Distribution of some metals in sediments of the central part of the Labe (Elbe) River, Czech Republic. Ambio 1993; 22:200-5.

Budimir $\mathrm{S}$, Marko B. Distribution of $\mathrm{Cd}, \mathrm{Pb}, \mathrm{Cu}$ and $\mathrm{Zn}$ in carbonate sediments from the Krka river estuary obtained by sequential extraction. Science of the Total Environment 1995;170:101-18.

Campanella L, Dorazio D, Petronio BM, Pietrantonio E. Proposal for a metal speciation study in sediments. Analytica Chimica Acta 1995;309: 387-93.

Che Y, He Q, Lin W. Study on heavy metals distribution in the south branch of Changjiang estuary. Shanghai Environmental Sciences 2002;21(4):220-3.

Chen S, Zhou J, Gu G. The distribution and shift of heavy metal elements in Changjiang estuary. Guangzhou Environmental Sciences 2001;16(1): $9-13$.

Davidson CM, Thomas RP, McVey SE, Perala R, Littlejohn D, Ure AM. Evaluation of a sequential extraction procedure for the speciation of heavy metals in sediments. Analytica Chimica Acta 1994; 291:277-86.

Davidson CM, Wilson LE, Ure AM. Effect of sample preparation on the operational speciation of cadmium and lead in a freshwater sediment. Fresenius' Journal of Analytical Chemistry 1999;363:134-6.

Fiedler HD, Lopez-Sanchez JF, Rubio R, Rauret G, Quevauviller PH, Ure AM, et al. Study of the stability of extractable trace metal contents in a river sediment using sequential extraction. Analyst 1994;119:1109-14.

Forstner U, Wittmann GTW. Metal pollution in the aquatic environment. Berlin: Springer-Verlag; 1979. p. 486.

Gomez Ariza JL, Giraldez I, Sanchez-Rodas D, Moralesm E. Metal sequential extraction procedure optimized for heavily polluted and iron oxide rich sediments. Analytica Chimica Acta 2000;414:151-64.

Ho D, Evans GJ. Operational speciation of Cadmium, copper, lead and zinc in the NIST standard reference materials 2710 and 2711 (Monatna soil) by the BCR sequential extraction procedure and flame atomic absorption spectrometry. Analytical Communications 1997;34:363-4.

Ildiko B, Klara P, Zsuzsanna C-H, Jozsef H. Sequential extraction procedure for the speciation of elements in fly ash samples. Microchemical Journal 1996;54:320-30.

Kersten M, Forstner U. Chemical fraction of heavy metals in anoxic estuarine and coastal sediments. Water Science and Technology 1986;18: $121-30$.

Lopez-Sanchez J-F, Sahuquillo A, Fiedler HD, Rubio R, Rauret G, Muntau H, et al. CRM 601, A stable material for its extractable content of heavy metals. Analyst 1998;123:1675-7.

Martin R, Sanchez DM, Gutierrez AM. Sequential extraction of U, Th, Ce, $\mathrm{La}$ and some heavy metals in sediments from Ortigas River, Spain. Talanta 1998;46:1115-21.

Mester Z, Cremisini C, Ghiara E, Morabito R. Comparison of two sequential extraction procedures for metal fractionation in sediment samples. Analytica Chimica Acta 1998;259:133-42.

Ngiam L-S, Lim P-E. Speciation patterns of heavy metals in tropical estuarine anoxic and oxidized sediments by different sequential extraction schemes. Science of the Total Environment 2001;275:53-61.

Panda D, Subramanian V, Panigrahy RC. Geochemical fractionation of heavy metals in Chilka Lake (east coast of India) - a tropical coastal lagoon. Environmental Geology 1995;26:199-210.

Pickering WF. Metal ion speciation-soil and sediments (a review). Ore Geology Reviews 1986;1:83-146.

Ramos L, Hernandez LM, Gonzalez MJ. Sequential fraction of copper, lead, cadmium and zinc in soils from or near Donana National Park. Journal of Environmental Quality 1994;23:50-7.

Salomons W. Adoption of common schemes for single and sequential extractions of trace metals in soil and sediments. International Journal of Environmental Analytical Chemistry 1993;51:3-4.

Serife T, Senol K, Latif E. Determination of heavy metals and their speciation in lake sediments by flame atomic absorption spectrometry after a four-stage sequential extraction procedure. Analytica Chimica Acta 2000;413:33-40.

Stalikas CD, Pilidis GA, Tzouwara-Karayanni SM. Use of a sequential extraction scheme with data normalization to assess the metal distribution in agricultural soils irrigated by lake water. Science of the Total Environment 1999;236:7-18.

Tessier A, Campbell PGC, Bisson M. Sequential extraction procedure for the speciation of particulate trace metals. Analytical Chemistry 1979; 51:844-51.

Thomas RP, Ure AM, Davidson CM, Littlejohn D, Rauret G, Rubio R, et al. Three-stage sequential extraction procedure for the determination of metals in river sediments. Analytica Chimica Acta 1994;286:423-9.

Tu Q, Shan X, Ni Z. Evaluation of a sequential extraction procedure for the fractionation of amorphous iron and manganese oxides and organic matter in soils. Science of the Total Environment 1994;151:159-65. 
Ure AM, Quevauviller Ph., Muntau H, Griepink B. Speciation of heavy metals in solids and harmonization of extraction techniques undertaken under the auspices of the BCR of the Commission of the European Communities. International Journal of Environmental Analytical Chemistry 1993;51:135.

Usero J, Gamero M, Morillo J, Gracia I. Comparative study of three se- quential extraction procedures for metals in marine sediments. Environment International 1998;24:478-96.

Zdenek B. Evaluation of the concentrations of trace elements in stream sediments by factor and cluster analysis and the sequential extraction procedure. Science of the Total Environment 1996;177:237-50. 